\title{
Winter Frost at Viking Lander 2 Site
}

\author{
THOMAS SVITEK AND BRUCE MURRAY
}

Divsion of Geological and Planetary Scrences, Calfornia Institute of Technology, Pasadena

\begin{abstract}
A key question in the study of Mars is water exchange between atmosphere and surface on daily, seasonal, and astronomical timescales. We believe that small-scale processes are a key for enhanced understanding of the global water behavior of Mars. The principal data for this study of small scale properties of the Martian surface were collected by the second Viking lander (VL 2) and by both Viking orbiters. The annual deposition and retreat of the frost layer were observed in situ by VL 2 . The frost is inferred to be $\mathrm{H}_{2} \mathrm{O}$ frost but with some properties suggesting a much thicker layer than would be expected from the simple mass balance calculation. Our original contribution is in considering the effect of cold trapping (frost redeposition) which has been previously neglected and which enables us to reconcile all the observations with environmental conditions. In addition, we believe that this study points to a more general phenomenon of cold trapping in the Martian environment. Our study of the VL 2 observations suggests that $\mathrm{H}_{2} \mathrm{O}$ frost occurs in two forms: (1) thin, almost continuous, early frost and (2) much thicker, patchy, later frost. Both frost forms contain essentially the same total water content, but they cover different fractions of the surface. The transition between the two frost forms occurs by recondensation at local cold traps when solar insolation sublimates the first frost but the atmosphere is still too cold to transport the resultant water vapor away. These cold traps are created by shadowing from the small-scale surface roughness, rocks, troughs, etc. This hypothesis hinges on the disparity between local and long-range transport of water vapor by the atmosphere. The local transport is driven by abundant insolation energy available at the time of transition. This results in a large fraction of surface frost being redistributed rapidly into locally thermodynamically preferable locations, cold traps. Long-range transport is constrained by the atmospheric carrying capacity. At the time of transition, the atmosphere is still cold, not far from its winter minimum, and is almost saturated by residual water vapor (5-8 precipitable micrometers). Therefore it cannot carry much additional water vapor to lower latitudes. This disparity delays the global transport of water vapor by the atmosphere.
\end{abstract}

\section{INTRODUCTION}

A key question in the study of Mars is water exchange between atmosphere and surface on daily, seasonal, and astronomical timescales [Jakosky, 1985]. The data from the Mariner 9 and Viking spacecraft present convincing evidence that substantial amounts of water modified the surface of Mars in the past [Carr, 1986]. However, at present, observable water exchange is limited to the dynamic behavior of the polar caps [Leighton and Murray, 1966] and to occasional frosts, fogs, and clouds [Christensen and Zurek, 1984] We believe that small-scale processes are a key to enhanced understanding of the global water behavior of Mars.

The principal data for this study of small scale properties of the Martian surface were collected predominantly by the second Viking lander (VL 2) (with its more poleward location) and by both Viking orbiters. The annual deposition and retreat of the frost layer were observed in situ by VL 2 . At the time of the Viking project, it was concluded that this frost represented the southernmost edge of the northern seasonal polar cap [Snyder, 1979]. However, the question of the composition $\left(\mathrm{H}_{2} \mathrm{O}\right.$ or $\mathrm{CO}_{2}$ ice) has persisted [Guinness et al., 1979; Jones et al., 1979] and is addressed here.

Wall [1981] published a study of the optical properties of the Viking Lander 2 frost. He showed that the measured phase function is consistent with a thickness of the frost layer on the order of several hundred micrometers. There is

Copyright 1990 by the American Geophysical Union.

Paper number 89JB03428.

0148-0227/90/89JB-03428\$05.00 not enough water vapor for such a thick layer of $\mathrm{H}_{2} \mathrm{O}$ frost to form simply by condensation from the Martian atmosphere [Davies et al., 1977]. Therefore Wall argued that this phase function interpretation indicated a $\mathrm{CO}_{2}$ not a $\mathrm{H}_{2} \mathrm{O}$ frost composition. Furthermore, there was only an increase of a few precipitable micrometers (at most) in the water vapor content of the atmosphere as frost disappeared in late winter. Later, Hart and Jakosky [1986] presented heat balance calculation. They concluded that this calculation precludes formation of the $\mathrm{CO}_{2}$ ice at this latitude and season and therefore argued instead for $\mathrm{H}_{2} \mathrm{O}$ ice as the Viking Lander 2 winter frost. However, this very important and critical conclusion has to be reconciled with the result of the Wall study. Hart and Jakosky [1986] suggested that frost photometric properties can be consistent with $10 \mu \mathrm{m}$ of $\mathrm{H}_{2} \mathrm{O}$ frost. But we think that there are two problems with this interpretation. First, the quoted $5 \%$ increase in reflectance is smaller by about a factor of 10 as compared with the reflectance increase which we measured. This will require frost of thickness much larger than $10 \mu \mathrm{m}$. Second, Hart and Jakosky [1986] suggested that deviations from Lambertian behavior of Wall [1981] could be explained by a much thinner layer than Wall proposed. But comparison with the original laboratory data of Smith et al. [1969] shows that these deviations from Lambertian reflectance are by far too small to admit a possibility of $10 \mu \mathrm{m}$ frost layer.

These contradicting conclusions from Wall [1981] and Hart and Jakosky [1986] intrigued us, and we undertook the work reported here. Our conclusion is that the VL 2 frost was $\mathrm{H}_{2} \mathrm{O}$ ice, concentrated by cold trapping due to local roughness at the VL 2 site and probably on much larger scale 
as well. This first conclusion $\left(\mathrm{H}_{2} \mathrm{O}\right.$ ice composition) follows closely the previous result of Hart and Jakosky [1986]. Our original contribution extending the previous work of Hart and Jakosky [1986] is twofold: First, we have considered in depth the photometric data obtained by an VL 2 imaging experiment and have been able to reconcile those with the calculation of thermodynamic stability of VL 2 frost. Second, we have developed a more detailed model of the water vapor transport in the boundary layer on Mars during the frost sublimation and redeposition. This model is an enhancement to a simpler model of Ingersoll [1970, 1974] and Toon et al. [1980] derived from terrestrial approaches. This model produces as its consequence a cold- trapping (frost redeposition) mechanism which has been previously neglected and which enables us to reconcile the "thick layer" results of Wall [1981] with the thermodynamic analysis of Hart and Jakosky [1986]. Our analysis of VL 2 frost is sufficiently complete to lead us to argue that some form of cold trapping must be a common attribute of the Martian environment in general.

Our study of the VL 2 observations suggests that $\mathrm{H}_{2} \mathrm{O}$ frost occurs in two forms: (1) thin, almost continuous, early frost (Figure 2) and (2) much thicker, patchy, later frost (Figure 3). Both frost forms contain essentially the same total water content, but they cover different fractions of the surface. The transition between two frost forms occurs by recondensation at local cold traps when solar insolation sublimates the first frost, but the atmosphere is still too cold to transport the resultant water vapor away. These lowerthan-average-temperature cold traps are created by shadowing from the small-scale surface roughness, rocks, troughs, etc.

This hypothesis hinges on the disparity between local and long-range transport of water vapor by the atmosphere. The local transport is driven by abundant insolation energy available at the time of transition. This results in a large fraction of surface frost being moved rapidly into thermodynamically preferable locations, cold traps. Long-range transport is constrained by the atmospheric carrying capacity. At the time of transition, the atmosphere was still cold, not far from its winter minimum, and was almost saturated by residual water vapor (5-8 precipitable micrometers). Therefore it cannot have carried much additional water vapor to lower latitudes. This disparity delayed the global transport of water vapor by the atmosphere.

In the next section of this paper, we present the environmental setting of the observational platform (Viking Lander 2) and summarize the data used in our study. In the third section, we describe the proposed concept and the physical processes operating at the VL 2 site. In the fourth section, we present the quantitative tests to which we subjected our hypothesis. In the fifth section, we discuss extensions of the concept to other situations as well as its limitations and delineate possible tests using future data. Last, we summarize of the concept of cold trapping at the VL 2 site and discuss its implications.

\section{Environmental SetTing}

The Viking Lander 2 landed on September 3, 1976, at Utopia Planitia, $47.96^{\circ} \mathrm{N}$ and $225.77^{\circ} \mathrm{W}$. The landing site is located on the ejecta debris blanket of the Mie crater about $200 \mathrm{~km}$ southwest. The lander sits on a boulder field, with fine dust and sand as substrate and with no clearly visible bedrock. The panoramic view from VL 2 northward is in Figure 1. Besides the top priority search for life, the landers conducted a series of meteorological and soil properties experiments. The following data were used during this study.

\section{Frost Surface Coverage and Color}

Two facsimile cameras on top of the lander body took almost 3000 images during the lifetime of VL 2 [Guinness et al., 1982; Arvidson et al., 1983]. About 600 of these were taken during the first and second winter and reveal the traces of the frost (Figures 2 and 3). A selected fraction of these images was used by us (Table 1) for measurement

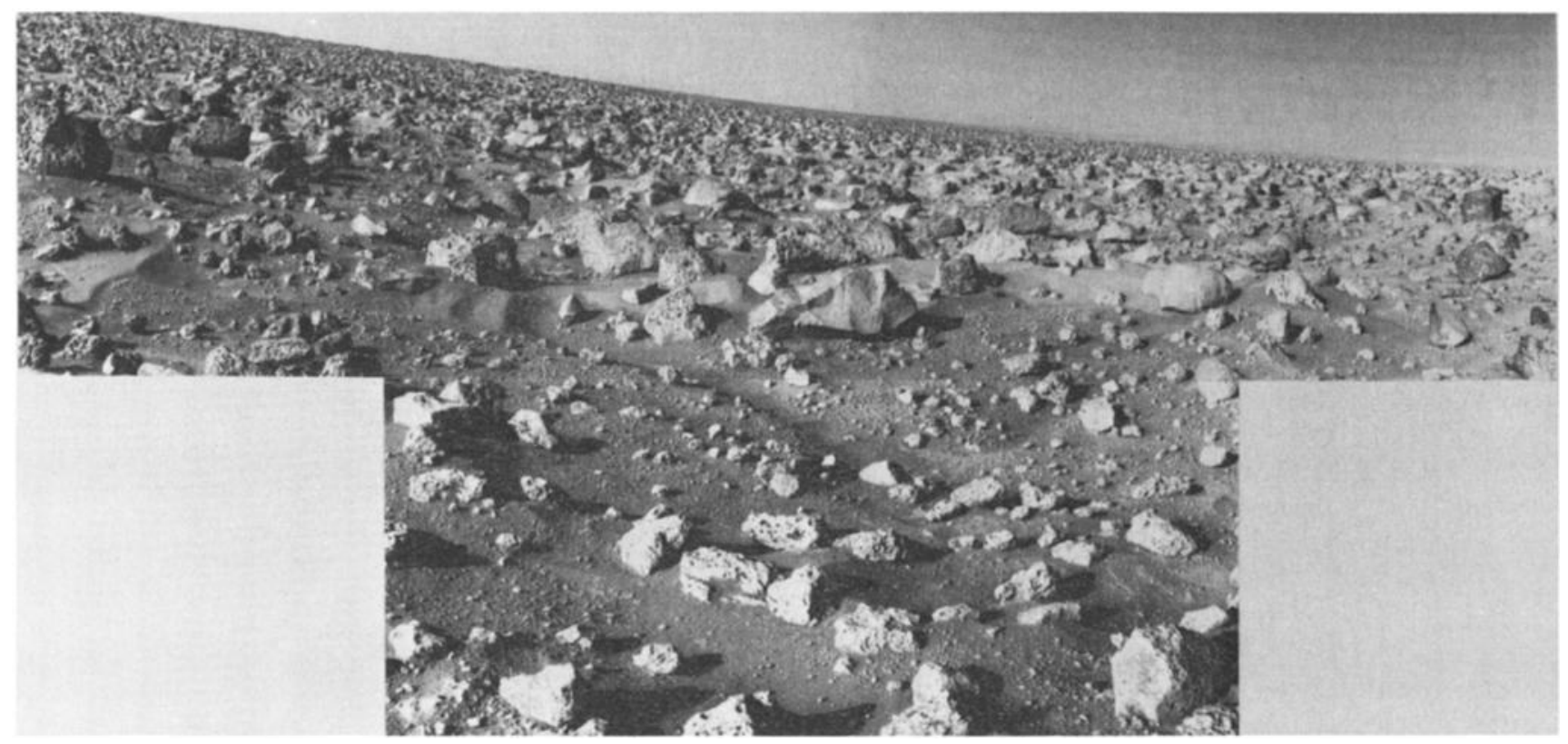

Fig. 1. VL 2 panorama. 


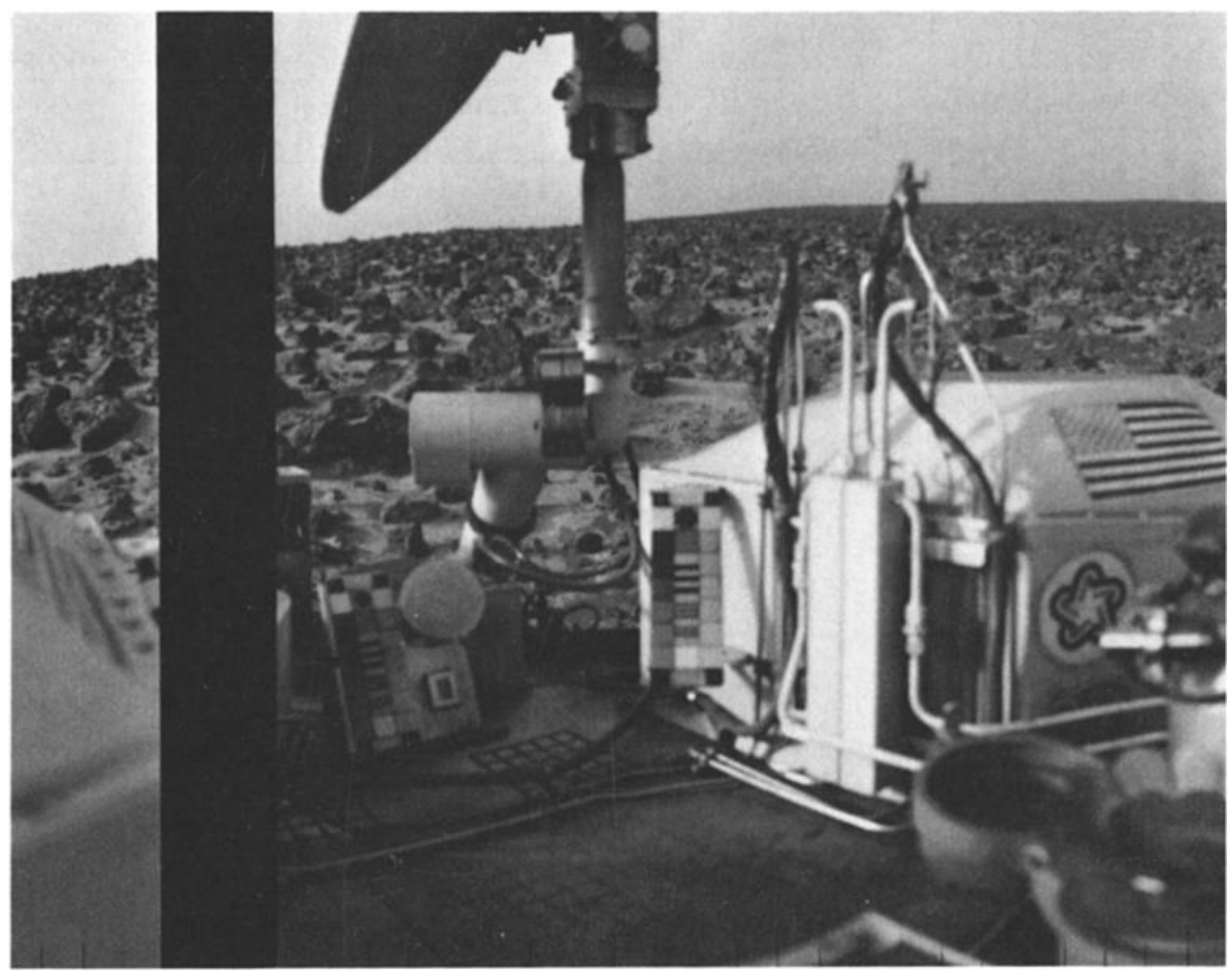

Fig. 2. Early continuous frost.

of the changes in frost surface coverage and in color as a function of $L_{s}$. The surface coverage measurement was performed by visually inspecting the images and using a grid overlay to estimate the frost covered fraction of the surface.

The color changes were measured by extracting pixel values (DN, data numbers) from the identified frost spots on the surface (Figure 4). This was made possible by a sequence of images of the same area taken in color triplets (through red, green, and blue filters), usually with the calibration target in the image and at the same local time (Table 2). This sequence was taken during the both winters and the measurement was repeated for both. The color change was measured by comparing DN values of frost, calibration target, lander cover, and bare soil in three color bands (red, green, and blue). Only relative color change (comparing different areas of frost) is required for the sake of the argument in this paper. Absolute color information is difficult to obtain because of uncertain calibration of cameras and poorly quantified effect of atmospheric scattering. For our analysis, the relative color change is important only at the time of transition between two frost forms.

Measurement of the frost brightness and color as a function of phase angle could yield further clues about the Martian soil roughness and frost deposition mode on the surface. However, as these are not directly relevant to this topic, they are not pursued further here.

\section{Atmospheric Temperature}

Temperature is a key parameter in any volatiles study. The primary use of temperature data in our study was to calculate the atmospheric holding capacity for water vapor. The first source of atmospheric temperature data was the lander itself [Hess et al., 1977]. The ambient temperature sensor was included as a part of the more comprehensive meteorological package and was measured at a height of about $1.5 \mathrm{~m}$. The Viking orbiter infrared radiometer (IRTM) in its $15-\mu \mathrm{m}$ band provided an indication of atmospheric temperature corresponding to a height of about $25 \mathrm{~km}$ [Kieffer et al., 1977]. This is about the maximum altitude where water vapor can make a noticeable contribution to the total atmospheric column under most of conditions. The possible exception is a temperature inversion which can happen under either one of these two conditions: (1) a vigorous dust storm or (2) surface covered by $\mathrm{CO}_{2}$ frost. At these conditions, most of the water vapor can be stored at this altitude of $25 \mathrm{~km}$. However, the season of our study is after the global dust storm, there is permanent $\mathrm{CO}_{2}$ frost deposit on the surface, and the large-scale thermal inversion at this latitude and season is not supported by VL 2 and IRTM data (temperature of IRTM $15-\mu \mathrm{m}$ band is consistently lower than temperature at the VL 2 site).

The synthesized vertical temperature distribution of the atmosphere and its diurnal variation above the VL 2 site is depicted in Figure 5. It is based on the following expression:

$$
\begin{aligned}
T(z) & =T_{s t}(z)+\Delta T \cdot e^{\left(-\frac{z}{z_{0}}\right)} \\
T_{s t}(z) & =T_{V L}+\left(T_{25}-T_{V L}\right) \frac{z}{25} \\
\Delta T & =\frac{\left(T_{V L \text { max }}-T_{V L \min }\right)}{2}
\end{aligned}
$$

where $T(z)$ is the atmospheric temperature, $z$ is the altitude (in $\mathrm{km}$ ), $T_{s t}$ is the steady temperature (without diurnal variation), $\Delta T$ is the diurnal excursion from the steady state in the thermal boundary layer, $T_{V L}$ is the ambient temperature at the Viking lander site, $T_{15}$ is the temperature measured 


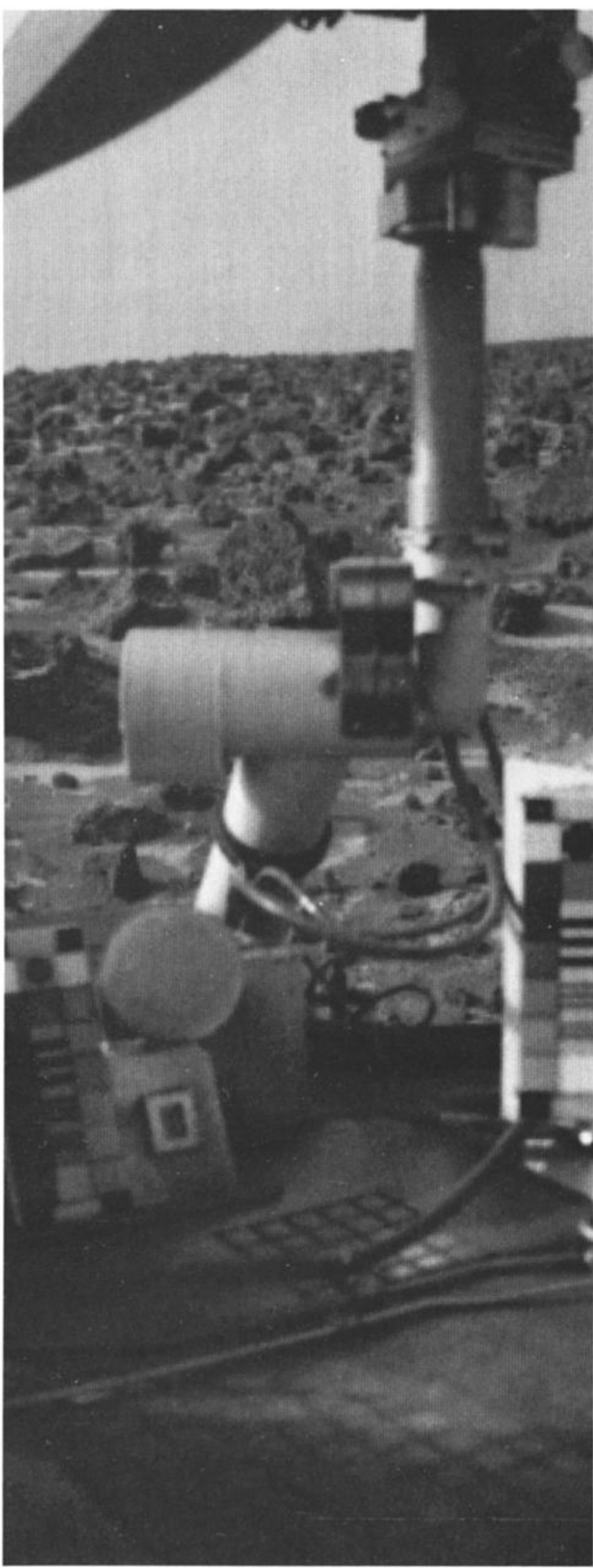

Fig. 3. Later patchy frost.

by the IRTM instrument at $15-\mu \mathrm{m}$ band, and $z_{0}$ is the thickness of the thermal boundary layer. The atmospheric thermal gradient is estimated by linear interpolation between the Viking lander near-surface measurement and the IRTM 25-km measurement.
TABLE 1. List of VL 2 Images Used to Study Surface Coverage of Frost and Results

\begin{tabular}{|c|c|c|c|c|}
\hline CE Label & Sol & $\begin{array}{l}L_{s}, \\
\text { deg }\end{array}$ & $\underset{\%}{\text { Cover, }}$ & $\begin{array}{c}\text { Uncertainty, } \\
\%\end{array}$ \\
\hline 22D180 & 233 & 251 & 75 & 25 \\
\hline 22D181 & 233 & 251 & 85 & 10 \\
\hline 21D198 & 245 & 259 & 70 & 15 \\
\hline 22D209 & 245 & 259 & 60 & 20 \\
\hline $22 \mathrm{D} 213$ & 245 & 259 & 85 & 10 \\
\hline $22 \mathrm{D} 220$ & 257 & 266 & 70 & 20 \\
\hline 21D224 & 257 & 266 & 75 & 10 \\
\hline 21D232 & 257 & 266 & 75 & 10 \\
\hline 22D249 & 269 & 274 & 70 & 15 \\
\hline $22 D 253$ & 269 & 274 & 85 & 10 \\
\hline 21E008 & 281 & 282 & 85 & 10 \\
\hline 21E016 & 281 & 282 & 90 & 5 \\
\hline 22E033 & 293 & 289 & 90 & 5 \\
\hline $22 \mathrm{E} 037$ & 293 & 289 & 85 & 20 \\
\hline 21E048 & 305 & 297 & 85 & 10 \\
\hline 21E056 & 305 & 297 & 92 & 5 \\
\hline 22E073 & 317 & 304 & 65 & 25 \\
\hline 22E077 & 317 & 304 & 65 & 25 \\
\hline 22E085 & 329 & 311 & 40 & 20 \\
\hline 22E088 & 329 & 311 & 50 & 30 \\
\hline 22E128 & 353 & 325 & 25 & 10 \\
\hline 21E153 & 365 & 332 & 20 & 10 \\
\hline 22E169 & 377 & 338 & 15 & 5 \\
\hline 21E187 & 382 & 341 & 20 & 5 \\
\hline 21E192 & 382 & 341 & 25 & 5 \\
\hline 21E194 & 382 & 341 & 15 & 5 \\
\hline $22 \mathrm{E} 211$ & 389 & 345 & 5 & 3 \\
\hline $21 \mathrm{E} 215$ & 389 & 345 & 10 & 3 \\
\hline 22E230 & 400 & 351 & 3 & 1 \\
\hline 22E247 & 406 & 354 & 3 & 1 \\
\hline 22F011 & 410 & 356 & 2 & 1 \\
\hline 21D184 & 233 & 251 & 85 & 10 \\
\hline 21D186 & 233 & 251 & 75 & 20 \\
\hline $21 D 192$ & 233 & 251 & 70 & 15 \\
\hline $21 D 193$ & 233 & 251 & 75 & 20 \\
\hline $22 \mathrm{D} 199$ & 245 & 258 & 50 & 20 \\
\hline 22D203 & 245 & 258 & 40 & 20 \\
\hline 22D227 & 257 & 266 & 40 & 10 \\
\hline $22 \mathrm{D} 231$ & 257 & 266 & 30 & 10 \\
\hline 21D233 & 257 & 266 & 60 & 15 \\
\hline $22 \mathrm{E} 035$ & 293 & 289 & 70 & 25 \\
\hline 22E038 & 293 & 289 & 75 & 25 \\
\hline 22E039 & 293 & 289 & 80 & 15 \\
\hline 21E040 & 293 & 289 & 80 & 10 \\
\hline 22E045 & 305 & 297 & 85 & 10 \\
\hline 21E048 & 305 & 297 & 85 & 10 \\
\hline $21 E 049$ & 305 & 297 & 85 & 10 \\
\hline 21E050 & 305 & 297 & 90 & 5 \\
\hline 22E051 & 305 & 297 & 70 & 10 \\
\hline
\end{tabular}

The Figure 5 profile is for $L_{s}=325^{\circ}$ and latitude of $48^{\circ} \mathrm{N}$, values approximate for the Viking Lander 2 site at the time of winter frost retreat. The thickness of the thermal boundary layer, the magnitude of the diurnal temperature variation near the surface, and the temperature profile are estimates based on these sources: (1) theoretical calculation of Flasar and Goody [1975], (2) General circulation model (GCM) simulation of Pollack et al. [1981], (3) the spacecraft occultation measurements [Davies, 1979b; Lindal et al., 1979], (4) Mariner 9 Infrared Interferometer Spectrometer (IRIS) atmospheric temperature profiles (M. Santee and D. Crisp, personal communication, 1989), and (5) calculation based diurnal variation of meteorological parameters at the Viking lander sites [Sutton et al., 1979]. The result is a compromise between the desire for accurate representation of the atmospheric temperature (particularly regarding the 
TABLE 1. (continued)

\begin{tabular}{|c|c|c|c|c|}
\hline CE Label & Sol & $\begin{array}{l}L_{8}, \\
\operatorname{deg}\end{array}$ & $\begin{array}{c}\text { Cover, } \\
\%\end{array}$ & $\begin{array}{c}\text { Uncertainty, } \\
\%\end{array}$ \\
\hline $\begin{array}{l}21 \mathrm{E} 052 \\
21 \mathrm{E} 054 \\
22 \mathrm{E} 055 \\
21 \mathrm{E} 057 \\
21 \mathrm{E} 058 \\
21 \mathrm{E} 059 \\
22 \mathrm{E} 071 \\
22 \mathrm{E} 075 \\
22 \mathrm{E} 078 \\
22 \mathrm{E} 085 \\
22 \mathrm{E} 088 \\
22 \mathrm{E} 091 \\
22 \mathrm{E} 092 \\
21 \mathrm{E} 094 \\
22 \mathrm{E} 095 \\
22 \mathrm{E} 098 \\
21 \mathrm{E} 099 \\
22 \mathrm{E} 111 \\
21 \mathrm{E} 113 \\
21 \mathrm{E} 114 \\
21 \mathrm{E} 117 \\
21 \mathrm{E} 119 \\
22 \mathrm{E} 128 \\
22 \mathrm{E} 129 \\
22 \mathrm{E} 136 \\
21 \mathrm{E} 153 \\
22 \mathrm{E} 169 \\
21 \mathrm{E} 227 \\
22 \mathrm{E} 230\end{array}$ & $\begin{array}{l}305 \\
305 \\
305 \\
305 \\
305 \\
305 \\
317 \\
317 \\
317 \\
329 \\
329 \\
329 \\
329 \\
329 \\
329 \\
329 \\
329 \\
341 \\
341 \\
341 \\
341 \\
341 \\
353 \\
353 \\
353 \\
365 \\
377 \\
398 \\
400\end{array}$ & $\begin{array}{l}297 \\
297 \\
297 \\
297 \\
297 \\
297 \\
304 \\
304 \\
304 \\
311 \\
311 \\
311 \\
311 \\
311 \\
311 \\
311 \\
311 \\
318 \\
318 \\
318 \\
318 \\
318 \\
325 \\
325 \\
325 \\
332 \\
339 \\
350 \\
351\end{array}$ & $\begin{array}{l}80 \\
60 \\
80 \\
85 \\
85 \\
80 \\
75 \\
70 \\
60 \\
70 \\
40 \\
50 \\
60 \\
60 \\
80 \\
50 \\
75 \\
85 \\
80 \\
80 \\
65 \\
80 \\
25 \\
25 \\
10 \\
25 \\
15 \\
3 \\
3\end{array}$ & $\begin{array}{c}15 \\
25 \\
5 \\
5 \\
5 \\
10 \\
15 \\
20 \\
20 \\
25 \\
30 \\
15 \\
20 \\
15 \\
5 \\
25 \\
5 \\
10 \\
5 \\
15 \\
15 \\
15 \\
5 \\
10 \\
5 \\
10 \\
5 \\
2 \\
2\end{array}$ \\
\hline $\begin{array}{l}22 I 057 \\
221058 \\
22 I 059 \\
22 I 060 \\
22 I 061 \\
22 I 062 \\
221063 \\
221066 \\
221067 \\
221075 \\
211093 \\
221096 \\
221097 \\
221098 \\
221099 \\
22 I 100 \\
22 I 101 \\
22 I 102 \\
21 I 105\end{array}$ & $\begin{array}{l}874 \\
886 \\
898 \\
910 \\
922 \\
934 \\
946 \\
955 \\
955 \\
955 \\
960 \\
967 \\
977 \\
987 \\
997 \\
100 \\
101 \\
102 \\
103\end{array}$ & $\begin{array}{l}233 \\
241 \\
249 \\
256 \\
264 \\
272 \\
280 \\
285 \\
285 \\
285 \\
289 \\
293 \\
299 \\
305 \\
311 \\
317 \\
323 \\
329 \\
334\end{array}$ & $\begin{array}{l}40 \\
40 \\
50 \\
70 \\
85 \\
85 \\
85 \\
85 \\
80 \\
85 \\
85 \\
75 \\
75 \\
75 \\
70 \\
60 \\
60 \\
55 \\
20\end{array}$ & $\begin{array}{l}30 \\
30 \\
20 \\
15 \\
10 \\
10 \\
10 \\
10 \\
15 \\
10 \\
10 \\
10 \\
10 \\
10 \\
10 \\
10 \\
15 \\
10 \\
5\end{array}$ \\
\hline $\begin{array}{l}221065 \\
211090 \\
211091 \\
221094\end{array}$ & $\begin{array}{l}955 \\
959 \\
959 \\
960\end{array}$ & $\begin{array}{l}285 \\
288 \\
288 \\
289\end{array}$ & $\begin{array}{l}60 \\
80 \\
65 \\
70\end{array}$ & $\begin{array}{l}30 \\
30 \\
15 \\
20\end{array}$ \\
\hline
\end{tabular}

sensitivity of water vapor pressure on temperature) and a realistic assessment of what is known about the atmospheric , state at this particular latitude and season.

The constant thermal gradient with diurnal perturbation is not that much different compared with one of the best sources of temperature profile data: from Mariner 9 IRIS experiment (M. Santee and D. Crisp, personal communication, 1989). This data set has a vertical resolution of about one scale height which hides possible thermal wave propagating upward (as seen in Viking lander temperature profiles during entry). But we are interested primarily in diurnal variations, not in the absolute value of atmospheric

Fig. 4. (opposite) Example of pixel retrieval processes.

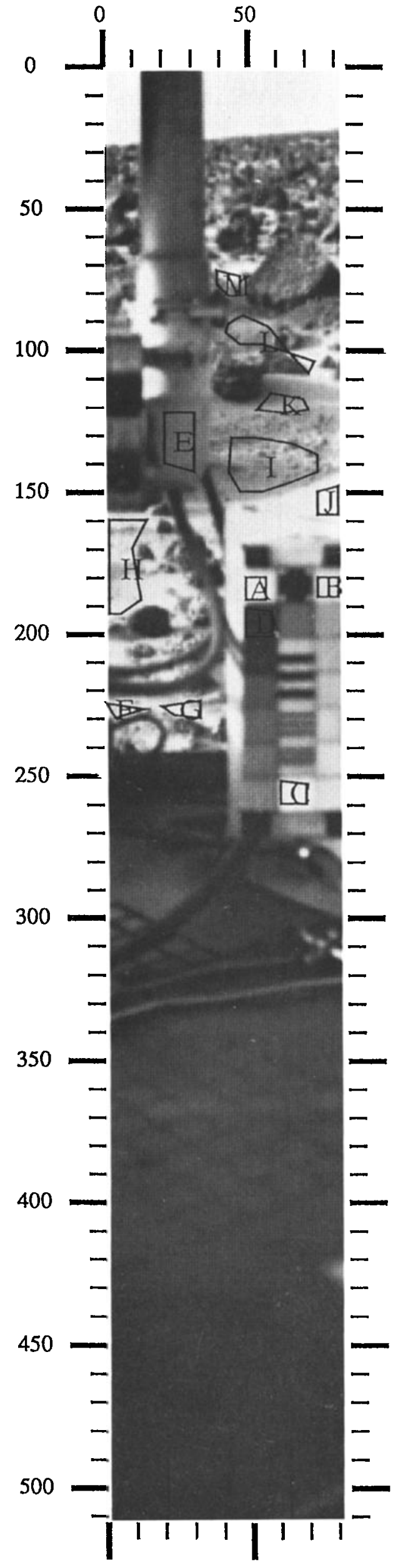


TABLE 2. List of VL 2 Images Used to Study Color Changes of Frost and Results

\begin{tabular}{rrrrrrc}
\hline CE Label & $\begin{array}{c}L_{s}, \\
\text { deg }\end{array}$ & Sol & White & Red & $\begin{array}{c}\text { Late } \\
\text { Frost }\end{array}$ & $\begin{array}{c}\text { Early } \\
\text { Frost }\end{array}$ \\
\hline 221057 & 233 & 874 & .9 & 2.7 & & 1.8 \\
221058 & 241 & 886 & 1.0 & 3.2 & & 1.9 \\
221059 & 249 & 898 & 1.0 & 3.1 & & 1.6 \\
221060 & 256 & 910 & .9 & 3.0 & .9 & 1.3 \\
221061 & 264 & 922 & .8 & & .9 & 1.1 \\
221062 & 272 & 934 & .9 & 3.0 & .9 & 1.0 \\
221063 & 280 & 946 & .9 & 2.9 & .8 & 1.0 \\
221066 & 285 & 955 & .8 & 2.8 & .8 & .9 \\
221067 & 285 & 955 & .8 & 2.8 & & .8 \\
221096 & 293 & 967 & .8 & 2.9 & 1.0 & 1.0 \\
221097 & 299 & 977 & .8 & 2.8 & 1.0 & 1.0 \\
221098 & 305 & 987 & .8 & 2.8 & 1.0 & 1.0 \\
221099 & 311 & 997 & .8 & 3.1 & 1.0 & 1.1 \\
221100 & 317 & 1007 & 1.0 & 3.0 & 1.0 & 1.1 \\
221101 & 323 & 1017 & .8 & 3.2 & .5 & 1.5 \\
221102 & 329 & 1027 & .8 & 3.2 & .6 & 1.6 \\
\hline
\end{tabular}

water vapor holding capacity. A pocket of warm air at 25 $\mathrm{km}$ altitude can potentially contain substantial amount of water vapor, but this does not mean that this water vapor is available for surface interaction on a diurnal time scale.

Further support for not considering a potential localized storage of water vapor at high altitudes comes from the following feedback: a higher degree of subadiabatic temperature profile will create more stable atmosphere, thus diminishing the effect of this high-altitude water. On the other hand, a closer-to-adiabatic temperature profile will enable more vigorous vertical mixing, but the amount of available water vapor will decrease. In both cases, this enables us to use the simplified model for vertical temperature profile as described above.

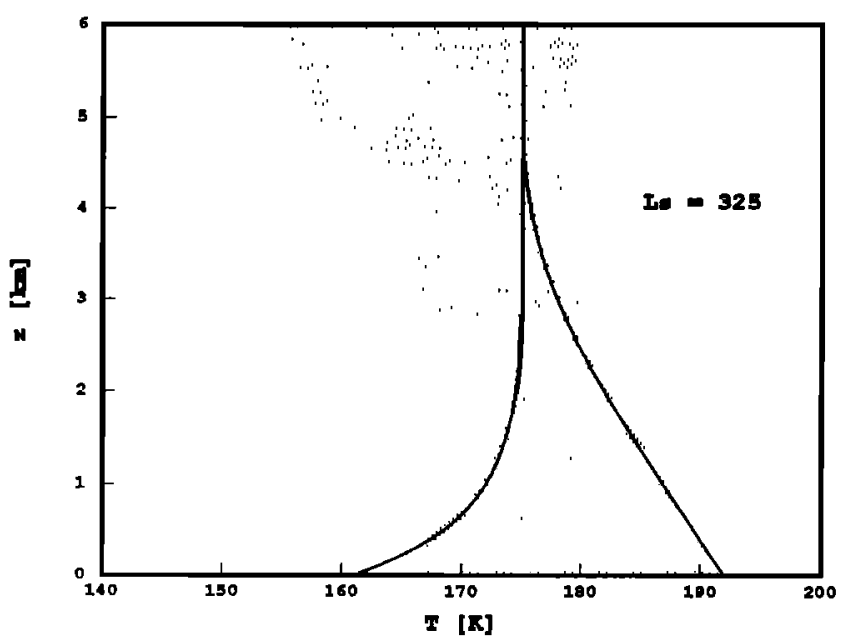

Fig. 5. Atmospheric vertical temperature profile and diurnal variation in thermal boundary layer. Minimum value (left boundary of the shaded region) would be for the adiabatic atmosphere starting with the temperature given by the ambient sensor on VL 2. The profile considered in our study is a linear interpolar tion between the surface temperature from VL 2 and temperature at the $25 \mathrm{~km}$ altitude from $15-\mu \mathrm{m}$ IRTM band. The extreme case (right boundary of the shadowed region) is for the thermal inversion during a dust storm. This inversion is not considered very likely at the time of our study (late winter).

\section{Atmospheric Water Vapor}

Later we used the thermal structure of the atmospheric boundary to calculate the atmospheric holding capacity and relative humidity. Results are summarized in Figure 6. The following expression was used to calculate the maximum column abundance of atmospheric water vapor in the units of precipitable micrometers:

$$
\Delta h=\frac{\mu}{\rho_{i c e}} \int \frac{p_{v}[T(z)] \cdot e^{(-\hbar)}}{k T(z)} d z
$$

where $\mu$ is the molecular weight of water, $\rho_{i c e}$ is the $\mathrm{H}_{2} \mathrm{O}$ ice density, $p_{v}(T)$ is the water vapor saturation pressure, $z$ is the altitude, and $H$ is the atmospheric scale height (assumed constant in our calculation). The shaded area in Figure 6 represents the variation derived from the diurnal VL 2 temperature cycle.

Viking orbiter water vapor column data from Mars Atmospheric Water Detector (MAWD) are also presented in Figure 6. In addition to the vertical temperature profile, the saturation by water vapor (relative humidity) depends also on the vertical distribution of water vapor. In contrast to the pre-Viking suggestions of strong water vapor concentration in the bottom few kilometers [Flasar and Goody, 1975], current understanding favors a more mixed state of the water vapor in the Martian atmosphere. Water vapor is expected to mix uniformly for at least two scale heights [Davies, 1979a]. There may be some enhancement of relative humidity in the bottom few kilometers, but this is primarily driven by diurnal variations in the thermal boundary layer. Atmosphere saturation near the surface on a diurnal basis is hinted at by several independent pieces of evidence: morn-

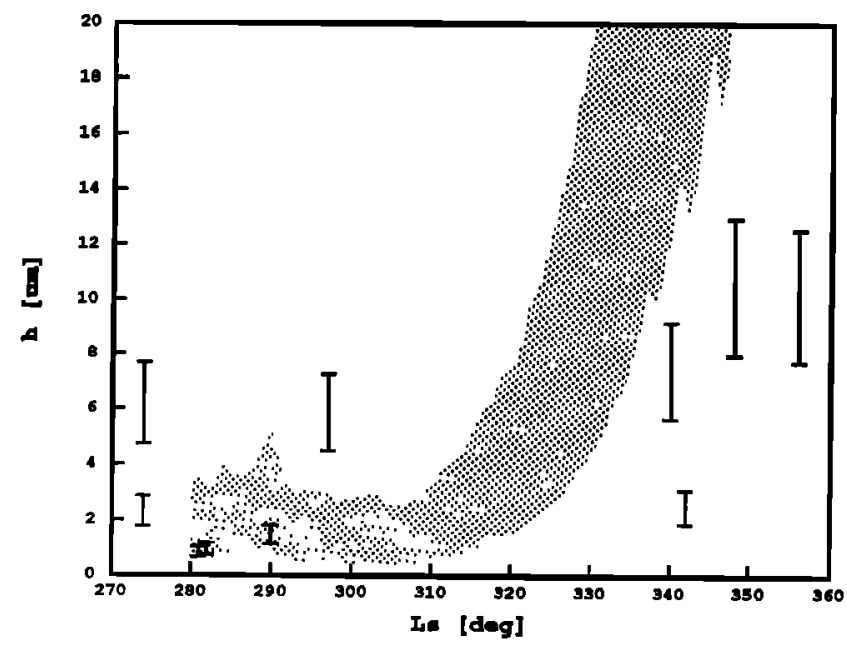

Fig. 6. Atmospheric holding capacity for water vapor above VL 2 site (in precipitable micrometers). The shaded region is the daily variation as calculated from the VL 2 ambient sensor and IRTM $15-\mu \mathrm{m}$ temperature. The small peak around $L_{s} \approx 290^{\circ}$ is because of the warmer atmosphere during the second dust storm. The irregularities at the minimum boundary at the late winter $\left(L_{s}>330^{\circ}\right)$ is an effect of the local VL 2 meteorology. The other data set in the graph is the MAWD measurement (averaged data points including error bars). It is important to note that during the late winter $\left(L_{s} \approx 330^{\circ}\right)$, the atmospheric water vapor content does not rise as rapidly as the atmospheric holding capacity for water vapor. 
ing fogs [Jakosky et al., 1988], diurnal optical depth variation [Pollack et al., 1979], and temperature inflection [Ryan and Sharman, 1981].

It can be noted that at the coldest period of the winter $\left(L_{s}<300^{\circ}\right)$, the observed MAWD water vapor column abundance is higher than the one calculated from the Viking lander surface temperature. This is due to the increased atmospheric temperature at altitude of $20-40 \mathrm{~km}$ due to the dust loading from the dust storms. Our model of the vertical temperature profile does not deal with this possibility, as mentioned above. This subadiabatic temperature profile could increase water vapor column abundance, probably combined with the transport from the lower latitudes. However, this effect becomes less important later $\left(L_{s}>300^{\circ}\right)$ because the atmosphere clears significantly and gets cooler. Also, water vapor at these altitudes does not readily exchange with the surface on the diurnal timescale. Therefore our calculations do not specifically apply to the possible water vapor which can be stored at these higher altitudes.

\section{Atmospheric Transport}

For the purpose of this study, it is necessary to estimate the vertical mixing and horizontal transport of water vapor in and out of the Martian atmosphere. This is, as might be expected, poorly known. In addition to the set of lander meteorology measurement (performed at the fixed height of only $1.5 \mathrm{~m}$ above the ground [Hess et al., 1977]), other sources are (1) the wind structure measured during the lander descent [Seiff and Kirk, 1977], (2) GCM simulations [Pollack et al., 1981], (3) Earth analogies [Sutton, 1953], and (4) theoretical calculations [Holton, 1979; Priestley, 1959; Plate, 1971]. More details will be presented in the relevant subsection on the physical processes of the proposed model.

However, there is important distinction regarding the calculation of vertical transport of water vapor from the surface to the atmosphere. On Earth, the greatest obstacle is formed by the boundary sublayer just above the surface (less than $1 \mathrm{~m}$ ). Once the water vapor gets above this sublayer, then further vertical transport is relatively fast compared with rate of saturation of the atmosphere with water vapor. Therefore a simple two-layer model can be used (Figure 7) (diffusion from infinite source (surface, e.g., ocean) to very large reservoir (atmosphere above the boundary sublayer) through narrow conduit (this boundary sublayer)) [Brutsaert, 1982]. In the first approximation, the rate of vertical transport which depends on the relative humidity above the boundary sublayer is not a function of itself. The transport above is fast enough to diffuse water vapor away into higher altitudes from above this sublayer. This keeps the relative humidity above the boundary sublayer only a slowly changing function of the vertical transport.

The situation on Mars is quite different. The rate of subli-
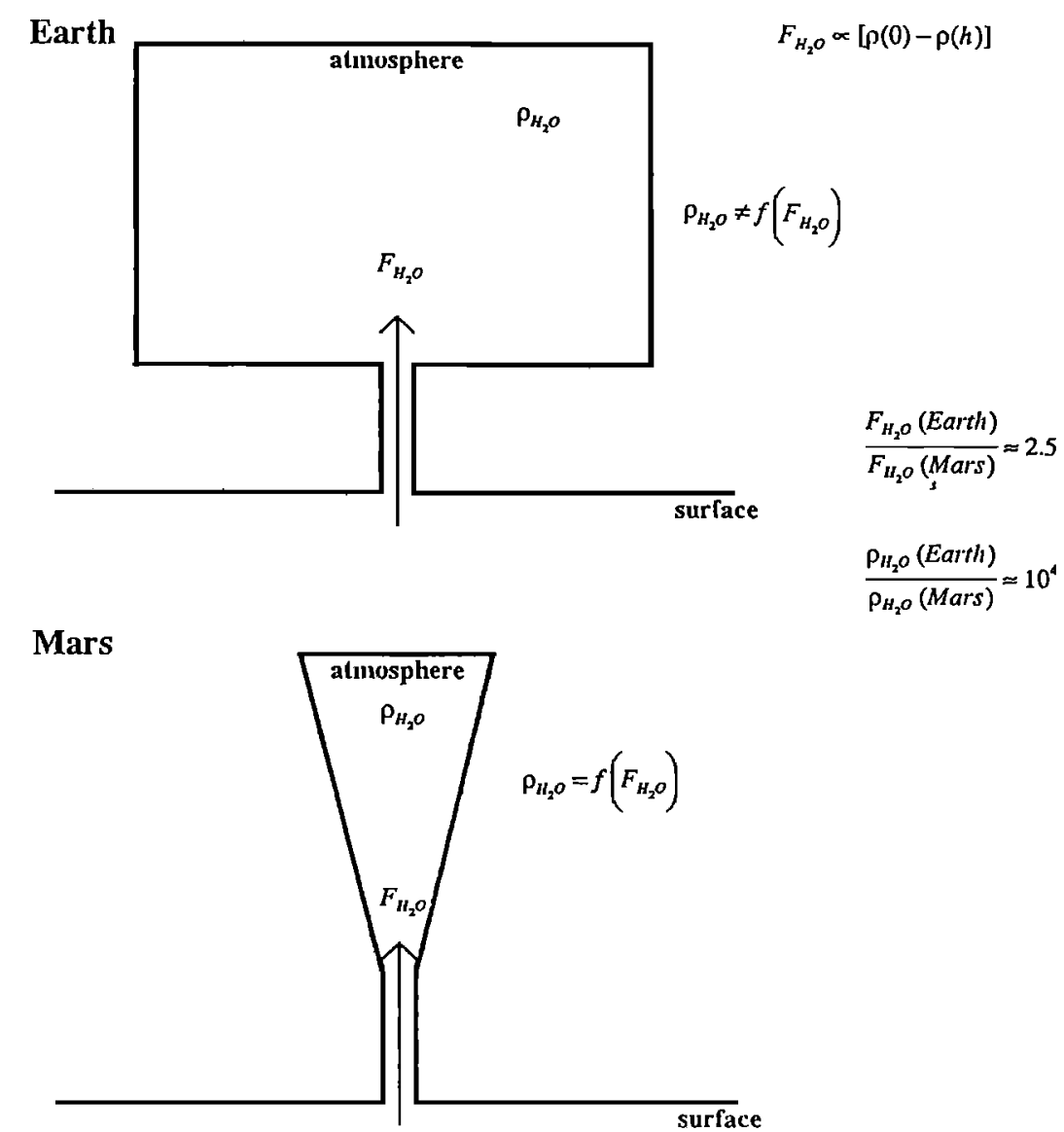

Fig. 7. Difference in boundary layer dynamics on Earth and on Mars. On Earth, the diffusion through the laminar sublayer just above the surface is the most limiting effect. The rate of diffusion through this layer does not depend on itself because the large available holding capacity of the atmosphere (even in very humid environment) above this sublayer. On Mars, situation is quite different (due to much lower atmospheric holding capacity for water vapor). Therefore the simple two-layer model cannot be used. 
mation (controlled by absorbed solar energy) is smaller only by a factor of about 2.3 . But the atmospheric water vapor holding capacity is lower by a factor of $10^{4}$. Therefore it is much easier to saturate the atmosphere near the surface. A model used to calculate the vertical transport of water vapor through the Martian atmosphere has therefore to take into account the implicit dependence of the vertical transport rate on itself. This then requires use of the multilayer model which keeps track of different level of saturation throughout the atmosphere.

\section{Surface Temperature}

Another important parameter for this study is surface temperature. This is required to calculate the frost stability on ground. Several sources of data were originally sought in order to assure the realistic understanding of the surface temperature. First, the Viking orbiter infrared radiometer IRTM had a $20-\mu \mathrm{m}$ band which gives surface temperature averaged over the field of view (typically $40 \mathrm{~km}$ [Kieffer et al., 1977]). Second, the footpad temperature sensor on the second leg of the lander (J. Tillman, personal communication, 1989) provided data on the surface temperature at the VL 2 site. Third, we performed the numerical calculation of surface thermal balance based on the solar energy, thermal radiation, and heat conduction into the ground (similar to Kieffer et al., [1977] and others). However, after comparing these data, we used for our analysis only the 20- $\mu \mathrm{m}$ IRTM measurements which we considered to be most reliable in spite of the averaging effect. Data from first two sources (IRTM and footpad) are compared in Figure 8. The footpad data are probably contaminated by the presence of the lander body, a source of thermal radiation and of shading by the Sun. The conduction of heat through the footpad was considered to negligible.

\section{Diffusion in the Soil}

We performed this part of our study in order to assure ourselves that the diffusion in and out of the soil can be neglected on the diurnal and subseasonal scale. For this cal-

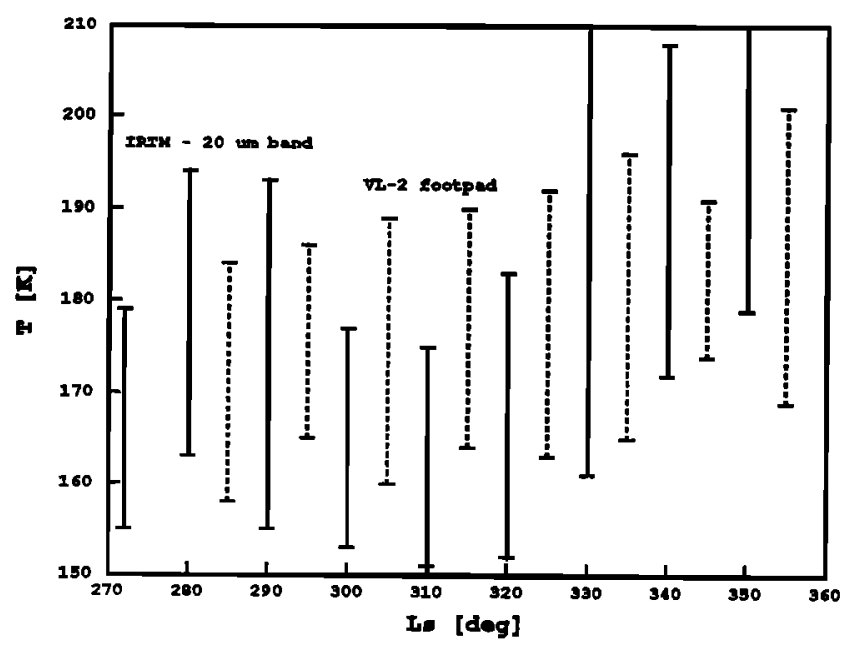

Fig. 8. Surface temperature from IRTM (solid line) and VL 2 footpad sensor (dashed line). The diurnal minimum and maximum are averaged over $10^{\circ}$ of $L_{s}$ (depicted by vertical bars). In the final analysis, only IRTM data were used, because the VL 2 footpad sensor data were probably contaminated by the presence of the lander body itself. culation, the critical parameter is the grain size distribution of the soil. We have tried to synthesize several independent pieces of evidence, namely (1) atmospheric scattering [Pollack et al., 1979; Zurek, 1982], (2) thermal inertia [Kieffer et al., 1977; Jakosky, 1986], (3) lander mechanical properties [Moore et al., 1987], (4) dust settling after landing, (5) phase function from orbit and Viking lander, (6) geology arguments (presence of dunes requires sand saltation [Sharp and Malin, 1984]), and (7) dust storm arguments (wind necessary to pick up dust grains and later settling). These considerations suggest the presence of a bimodal size distribution of dust/sand particles: (1) very fine dust (micrometer and submicrometer size) which constitutes the atmospheric dust and (2) coarser particles (hundreds of micrometers in size, maybe bonded together) which constitute most of the mass of surface material [Moore et al., 1987]. In most cases, the diffusion properties of the material would be controlled by smaller size particles. Approximate analysis, as well as careful calculation, by Zent et al. [1986], Clifford and Hillel [1986], Jakosky [1983], Toon et al. [1980], and Flasar and Goody [1975] shows that in this case, the magnitude of atmosphere/regolith interactions (diffusion in regolith, adsorption on regolith) will be negligible on a diurnal time scale. This, of course, applies only to the area and time we have studied (VL 2 winter frost).

\section{Proposed Model of Cold Trapping}

A sketch of the proposed model is shown in Figure 9. Our study of the Viking Lander 2 observations suggests that $\mathrm{H}_{2} \mathrm{O}$ frost occurs in two forms: (1) thin, almost continuous, early frost (Figure 2) and (2) much thicker, patchy, later frost (Figure 3). Both frost forms contain essentially the same total water content, but they cover different fractions of the surface. The transition between two frost forms occurs by recondensation at local cold traps when solar insolation sublimates the first frost, but the atmosphere is still too cold to transport the resultant water vapor away. These cold traps are created by shadowing from the small-scale

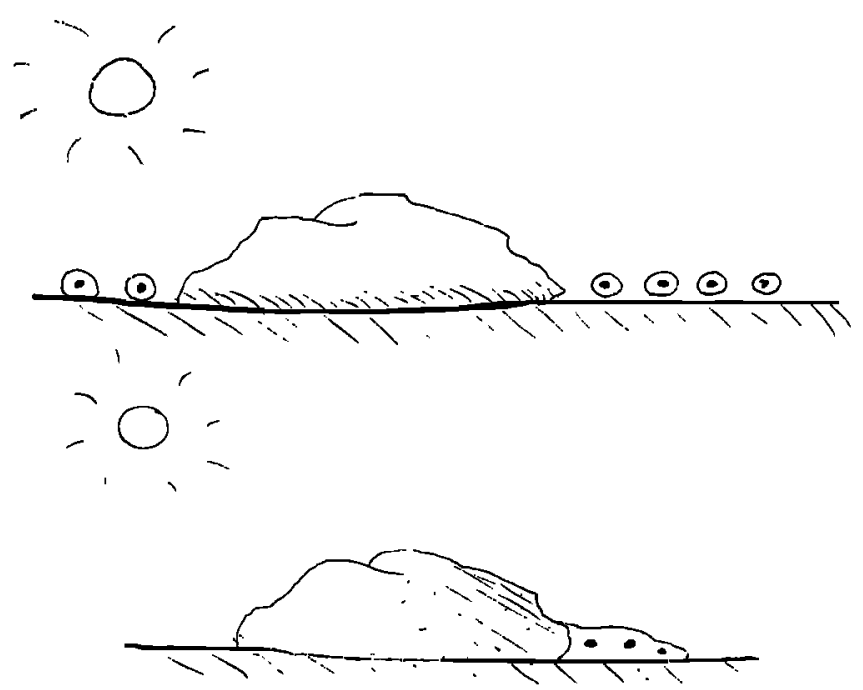

Fig. 9. Cartoon of the model. Two forms of frost: (a) Early frost is a thin layer $(10-20 \mu \mathrm{m})$, almost continuous surface coverage. (b) Later frost is a thicker frost (100-200 $\mu \mathrm{m})$, fraction of surface ("cold traps"). (c) Transition is timing by surface temperature $\left(L_{s} \approx 315\right.$ ), limited atmospheric transport process redeposition at locally favorable areas. 
surface roughness, rocks, troughs, etc. The critical feature of the hypothesis is disparity between local and long-range transport of water vapor by the atmosphere which delays the release of water vapor into atmosphere. In order to explain our model of $\mathrm{H}_{2} \mathrm{O}$ behavior, we must discuss frost sublimation and condensation, surface thermal balance, and water vapor transport in the boundary layer.

\section{Sublimation of Frost}

Water on the Martian surface occurs in only two phases: solid and vapor. The solid and vapors are in equilibrium if the partial pressure of water above solid ice follows this relation [Dorsey, 1940]:

$$
\log \left[p_{v}(T)\right]=\frac{A}{T}+B \cdot \log (T)-C \cdot T+D \cdot T^{2}-E[\mathrm{~Pa}]
$$

where $A=-2445.6, B=8.23, C=-0.01677, D=1.2 \mathrm{E}-5$, and $E=-7.781$. This is independent of the total ambient pressure created by other gases $\left(\mathrm{CO}_{2}\right.$ in this case). The transition from one phase to another is accompanied by the release or absorbtion of latent heat:

$$
L(T)=A-B(T+C)^{2}\left[\frac{\mathrm{J}}{\mathrm{kg}}\right]
$$

where $A=2.839 \mathrm{E} 6, B=3.6$, and $C=35$.

The water ice becomes unstable by either increase of the temperature of the solid phase or depletion of the vapor phase above the ice. Kinetics of transition from solid to vapor phase can be calculated in four possible regimes: molecular flow, molecular diffusion, forced convection, and free convection.

Molecular flow occurs at low temperatures where interactions between vapor molecules can be ignored because of low density of the vapor. This can be a relatively rapid form of sublimation limited only by energy input and the kinetic rate $\left(\approx 10^{-2} \mu \mathrm{m} \mathrm{s} s^{-1}\right.$ at the typical VL 2 winter temperatures):

$$
\frac{d h}{d t} \sim \frac{\mu \cdot p_{\nu}(T) \cdot \nu_{t h}(T)}{\rho_{s} \cdot k T} \sim \frac{\rho_{\nu}(T)}{\rho_{s}} \cdot \nu_{t h}(T)
$$

where $h$ is the frost layer thickness, $\mu$ is the molecular weight, $p_{\nu}$ is the vapor pressure, $\nu_{t h}$ is the thermal velocity of vapor, $\rho_{s}$ and $\rho_{\nu}$ are the solid and vapor phase densities. However, the conditions for this type of sublimation are truly valid on Mars only in a very thin layer just above the frost (approximately a few micrometers). On a larger scale, some of the following mechanisms have to be considered.

Molecular diffusion is important in the stably stratified atmosphere or in the laminar sublayer which occurs just above the surface (on scale of $0.01-0.1 \mathrm{~m}$ ). The coefficient for the molecular diffusion of $\mathrm{H}_{2} \mathrm{O}$ through $\mathrm{CO}_{2}$ gas at the Martian temperatures is typically $0.001 \mathrm{~m}^{2} \mathrm{~s}^{-1}$. This would limit the water frost sublimation to only about $0.1 \mu \mathrm{m}$ on a diurnal basis; this is based on the typical molecular diffusion distance of $10 \mathrm{~m}$ in 1 day. The remainder of solar energy input would go into increased temperature, leading to corresponding higher vapor pressure.

This situation will last until the lower molecular weight of $\mathrm{H}_{2} \mathrm{O}$ (as compared to $\mathrm{CO}_{2}$ ) causes unstable stratification quite analogous to the thermals found during hot days on Earth [Ingersoll, 1970]. This free convection environment does not practically limit water vapor sublimation; in this case the frost sublimation is limited by solar energy input.

Even if the situation described above requires in principle very little water vapor to decrease the average molecular weight of the gas, in the practical situation the inertial forces will limit this phenomenon to rather high mixing ratio of water vapor to carbon dioxide which in turn is possible only at a temperature closer to the melting temperature. Therefore forced convection is the most probable concept for the water frost sublimation at the VL 2 site. Knowledge of the wind profile of the boundary layer is necessary in order to quantify this loss mechanism. Diffusion using an eddy mixing coefficient represents the simplest approach (see later in this section).

\section{Condensation of Frost}

The opposite process to sublimation is condensation. Careful understanding of this process is required for any cold-trapping hypothesis. Water vapor is depleted from the atmosphere by coming into contact with the surface at a temperature lower than the temperature corresponding to the water vapor partial pressure $p_{V}(T)$. This "cold finger" mechanism is complicated on Mars by the presence of noncondensable gas, $\mathrm{CO}_{2}$. Therefore water vapor has to diffuse in on the surface from the $\mathrm{CO}_{2}$ atmosphere and latent heat has to get away, by radiation, conduction, or convection. From the Earth analogs, we assume the existence of a laminar sublayer in the boundary layer which has a thickness several times less than the typical surface roughness [Priestley, 1959]. The effectiveness of cold trapping depends on the rate of (1) heat transfer through this laminar sublayer and (2) water vapor molecular diffusion through the same layer.

First, the heat transfer rate is dominated by the radiative transfer. This easily removes latent heat released by the condensing water vapor. The increase in surface temperature by a degree kelvin will suffice to remove latent heat generated by water vapor condensing at the rate of $2 \mu \mathrm{m} \mathrm{h}^{-1}$. This figure $\left(2 \mu \mathrm{m} \mathrm{h}^{-1}\right)$ is about the most extreme upper limit on the frost deposition rate on the surface, and latent heat can still be removed by only a slight increase in the surface temperature. Therefore the removal of latent heat will not constitute the limiting factor on the water frost condensation on the surface. Second, the water vapor diffusion, through this laminar sublayer composed of a noncondensable gas, could be the other limiting factor. The magnitude of a diffusion rate can be estimated from $x^{2} \approx D t$. For $D \approx 0.001 \mathrm{~m}^{2} \mathrm{~s}^{-1}$ and $x \approx 1 \mathrm{~mm}$, we get $t \approx 1 \mathrm{~ms}$ which is much less than would be required for any reasonable rate of water vapor condensation. Therefore this analysis of water vapor condensation in the presence of $\mathrm{CO}_{2}$ suggests that the water vapor condensation on colder spots of the surface (cold traps) will occur at the rate controlled by supply of water vapor and will not be limited by presence of noncondensable gas.

Another factor which should be included is the accommodation coefficient of water molecule condensation on rock or ice surface. Unfortunately, the reliable measurements performed under the postulated Martian conditions are scarce, and therefore this effect is not further quantified here. We assume the value of accommodation coefficient to be 0.8 as we have no reason to believe that this value should substantially smaller than unity. 
We have also considered another postulated mechanism for condensation, on nuclei (dust grains) in the atmosphere. However, this cannot be important on a diurnal time scale. The fall-out rate for dust grains is significantly more than 1 day [Pollack et al., 1979]. Therefore the amount of water frost deposited on the surface is not more than a small fraction of micrometers per day. This can be estimated as follows: a "precipitable" layer of suspended dust (1-5 $\mu \mathrm{m}$ assuming micrometer sized particles and optical depth $\tau \approx$ $1-3)$ times the ice/dust mass ratio of nuclei $(\approx 1)$ divided by dust decay time scale (20-50 days). This mechanism, in order to be effective, would require very large grains with unrealistically thick water frost envelope. However, this mechanism may prevail during the initial deposition of frost on the surface in the late fall [Pollack et al., 1979] when deposition rates are 10-100 times slower.

\section{Thermal Balance of Thin Frost Layers}

When describing the thermal balance of thin ice layers, several nontrivial effects must be considered: albedo, thermal emissivity, phase function. The effectiveness of masking underlying color (i.e., red soil) of substrate depends on the frost structure (grain size and form of deposition) as well as the thickness. Therefore a precise calculation is very difficult, but experimental data [Clark, 1980; Warren, 1982] are consistent with our assumptions and measured optical properties: The water frost layer thickness of about 10-20 $\mu \mathrm{m}$ (early frost covering completely the surface) will not be able to mask the underlaying red color of the substrate, so the frost will have reddish tint. The water frost layer which is 100-200 $\mu \mathrm{m}$ thick (which is suggested for the later frost in cold traps) could have a largely white color, if we ignore a possibility of contamination by dust.

One interesting suggestion is the solid state greenhouse effect caused by solar heating beneath an ice layer. However, the key argument is that no significant temperature gradient can be sustained by such a thin layer, as can be shown by a simple numerical analysis (B. Jakosky, personal communication, 1989).

In addition to this effect, the reverse phenomenon has to be considered as well, which we call "inverse" greenhouse effect lacking better terminology. By this, we mean the effect of thinness of the frost layer on thermal emission from the frost. Because the frost changes the color of the surface, it has to absorb some fraction of sunlight. However, the expected early frost thickness $(10-20 \mu \mathrm{m})$ is about the same as a thermal wavelength. This could cause the emissivity to be significantly lower than unity which would not allow the frost to reradiate all the solar radiation that it receives in shorter wavelengths. This excess energy would have to be conducted into the underlaying soil and thus would cause a thermal gradient at the frost/soil interface. The frost will be warmer than the soil, which is quite opposite to what is normally understood as a solid-state greenhouse. However, as in the previous paragraph, any thermal effect will be negligible for such a thin layer. But this implies that it may be quite difficult to see such a frost layer in thermal wavelengths.

Thin frost layer can also have a profound effect, in principle, on the phase function in reflection. There are suggestions [Smith et al.,, 1969] that thin frost layers (less than about $200 \mu \mathrm{m}$ ) can exhibit a substantial specular reflection peak. This is to be compared to the Lambertian reflection of more massive layers. Unfortunately, there are essentially no laboratory data demonstrating the effect of grain size on phase function of thin frost layers [Warren, 1982], and therefore we did not consider the absence of a specular reflection to be a reliable indicator of thickness.

\section{Surface Roughness and Water Frost Stability}

Using the estimates of solid/vapor transition, sunlight absorbtion, and thermal emission, it is feasible to calculate stability of water frost deposited on a surface. The temperature of the frost must be between a minimum temperature corresponding to the partial pressure of water vapor in the atmosphere (for unlimited water frost supply), and a maximum temperature corresponding to that a nonvolatile material of the same albedo as the frost would achieve due to solar insolation and reradiation (for a fully saturated atmosphere). We assume the horizontal dimensions of the frost patch are greater than the scale for the horizontal heat transport from the bare, darker surface on the diurnal time scale. (If this is not so, the stability of frost patch will be diminished.) This "critical" distance is about $15 \mathrm{~cm}$ and is basically several times larger than the diurnal thermal skin depth.

Another effect influencing the surface frost stability is the small-scale surface roughness created by rocks, troughs, etc. Small-scale surface roughness has three thermal effects which are difficult to model precisely: (1) the nonuniform sunlight distribution, (2) the subsurface horizontal heat flow, and (3) the radiation shadowing of the surface. Fortunately, for the purpose of our study, only the magnitude of these effects is needed. A point calculation shows that the net effect of roughness on temperature of parts of surface in shadow (potential cold traps) is to moderate the temperatures extremes. (On the other hand, the surface which is more exposed to sunlight due to roughness would experience larger temperature extremes.) This is due to less insolation during the day (lower maximum temperature) as well as due to smaller exposure to the cold space during the night hence leading to smaller losses by thermal radiation (higher minimum temperature).

This concept can be further extended and the effect of small-scale roughness be estimated as follows: Let us assume that there is a certain fraction of the sky $(\beta)$ which is obscured from the sunlight and at the same time radiation shadowed. Obviously, different spots on the surface will have this insolation/thermal radiation pattern differently. However, averaging over the diurnal skin depth and averaging for a large number of cold traps will cause this shadowing/obscuration factor to not vary too much (as we have convinced ourselves by a numerical statistical analysis). Then we can introduce this factor into standard thermal balance equation, and quite simple manipulation of the heat diffusion equation will show that the random smallscale roughness has the similar effect as the increase in thermal inertia $I$ :

$$
\Delta I \sim I \cdot \beta
$$

The net effect of this increase of thermal inertia will be an increase in frost stability, therefore a decrease in the overall rate of sublimation. This is because most of the frost sublimation occurs during the peak temperature in the day, and this peak temperature is lower for the higher thermal inertia.

\section{Calculated Frost Thickness}

In our work, we have used a simple one-dimensional finite difference thermal diffusion model with the radiative bound- 
ary condition on the top, with the latent heat contribution from $\mathrm{H}_{2} \mathrm{O}$ sublimation and deposition, and with the proper solar insolation geometry.

We have adjusted values of the atmospheric optical depth and thermal infrared atmospheric downward flux until we were able to replicate the IRTM surface temperature measurement. This was with no frost deposition or sublimation. The thermal inertia was kept constant at $I=6.5$ (in units of $\left.10^{-3} \mathrm{cal} \mathrm{cm}^{-2} \mathrm{~s}^{-1 / 2} \mathrm{deg}^{-1}\right)$. The next step was to calculate the thickness of water frost deposited/sublimed using the parameters from above. The frost deposition/sublimation was in the molecular flow regime, limited only by the energy balance and the kinetic rate. Results are presented in Figure 10, which shows the thickness of deposited or sublimed frost layer for two situations (frost in full sunlight, frost in partial shadow) as a function of $L_{\theta}$. The values for the frost in full sunlight is for the thermal inertia given above $(I=6.5)$. The values for the frost in partial shadow comes from the model with the increased thermal inertia $(I=7.7)$ which corresponds to $\beta=0.2$ (obscuration/shadowing of sunlight is $20 \%$, probably typical for residual frost patches at the Viking Lander 2 site). The frost deposition was calculated from amount of latent heat necessary to keep surface temperature at a value corresponding to saturation pressure of water vapor derived from MAWD measurement. This, of course, assumes practically unlimited supply of water vapor from the atmosphere, which in turn would require very large vertical mixing in the atmosphere.

Therefore we do not expect this calculation to yield realistic values for frost deposition and sublimation because we neglected the atmospheric effects (limited atmospheric transport and boundary layer mixing, see below). The values in Figure 9 are overestimated by a factor of several. But the purpose of this exercise is threefold. First, it predicts a fairly accurate time when the net sublimation of water frost exceeds the net deposition and therefore when we should expect the frost layer to break up. Second, it shows that the difference between net sublimation for the fully illuminated frost and shadowed frost is about $20^{\circ} L_{s}$ (which is consistent with the Viking Lander 2 images).

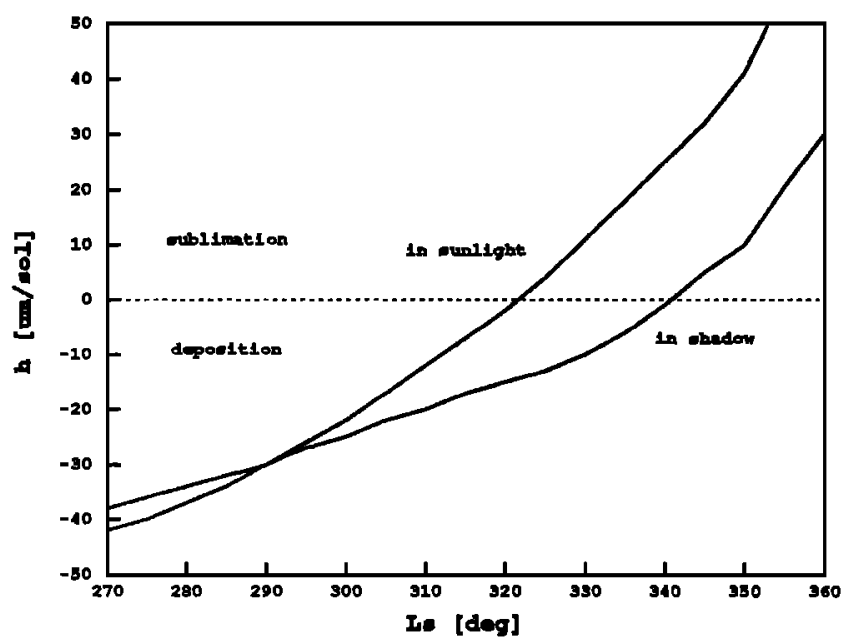

Fig. 10. Thickness of sublimed frost layer in one sol for two different situations (frost in full sunlight, frost in shadow) as a function of $L_{s}$. The calculation is based only on thermodynamical balance and does not include mixing in the boundary layer and cold trapping.
Third, the primary constraint on the behavior of water frost at this site is overwhelmingly the atmospheric effects (i.e., vapor supply, boundary layer mixing). Once the solar energy input reaches sufficient level for the net water frost sublimation, then in just a few days it can sublime more water frost than we could ever expect in the continuous deposit on the surface at the Viking Lander 2 site. This is, of course, inconsistent with the observed behavior (we see the water frost stays for much longer than a few days, it is stable for up to 80 sols).

The work described in this section follows closely a previous study of Hart and Jakosky [1986]. In addition, we have added the consideration of shadowed frost and further extended the model with boundary layer transport and frost recondensation. We believe that these three effects (shadowing, boundary layer transport, recondensation) have profound implications for behavior of water at VL 2 site and possible at other locations.

\section{Boundary Layer Transport}

To deal with water vapor mixing and transport in the boundary layer adequately, we have striven to create a welldefined subset of assumptions which would be consistent with the inadequately known structure of the atmospheric boundary layer on Mars. The components of the wind in the boundary layer are

$$
\begin{gathered}
u=\langle u\rangle+u^{\prime} \\
w=\langle w\rangle+w^{\prime}
\end{gathered}
$$

where $\langle u\rangle$ and $\langle w\rangle$ designate the mean velocity and $u^{\prime}$ and $w^{\prime}$ designate the deviation from the mean. We are considering only the two-dimensional model with horizontal and vertical winds. We also assume the vertical atmosphere motion will average to zero $(\langle w\rangle=0)$. We further assume the logarithmic wind profile [Holton, 1979] for the surface layer (the thickness of which is of the order of meters or tens of meters):

$$
\langle u\rangle=\frac{u_{*}}{k} \ln \left(\frac{z}{z_{0}}\right)
$$

where $u_{*}$ is the friction velocity, $k$ is the Karman constant experimentally determined to be about $0.4, z$ is the altitude, and $z_{0}$ is the roughness length. This length is approximately an order of magnitude smaller than the physical size of surface roughness [Priestley, 1959]. The friction velocity $u_{*}$ defined as:

$$
u_{m}^{2} \equiv\left(\frac{\tau_{x}}{\rho}\right)_{s}
$$

where $\tau_{x}$ is the surface stress and $\rho$ is the atmospheric density. The diffusion calculation employs the idea of an eddy diffusion coefficient which can be estimated from

$$
K \frac{\partial u}{\partial z}=u_{*}^{2} \Rightarrow K=k \cdot u_{*} \cdot z=u_{*} \cdot l
$$

where $l$ is the mixing length. This surface layer with the logarithmic wind profile extends to a height of about

$$
h \sim 0.2 \frac{u_{*}}{f}
$$

where $f$ is the Coriolis parameter. Above the surface layer, the eddy diffusion coefficient $K$ in the Ekman layer is independent of height. This is the result of the assumption 


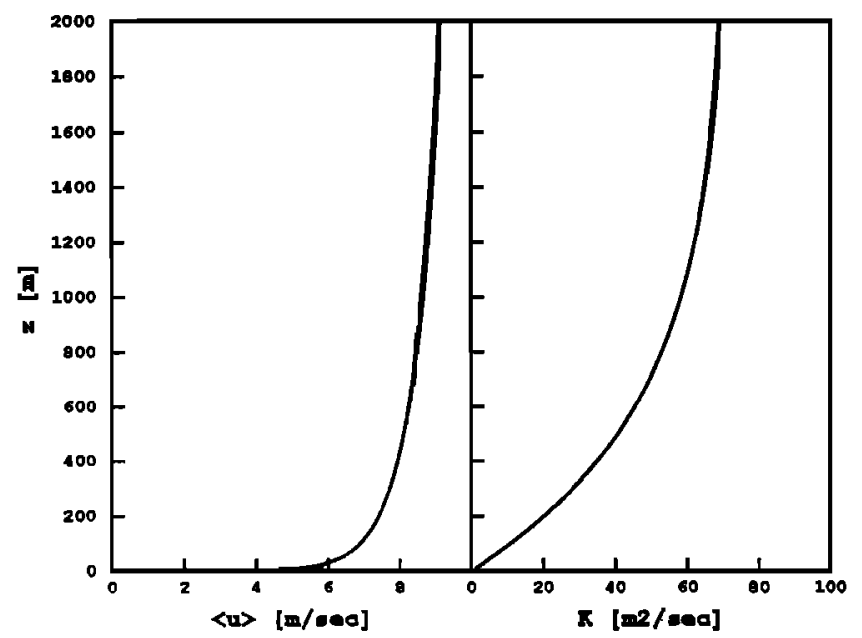

Fig. 11. Synthetic atmospheric profile, zonal winds $\langle w\rangle$ and war ter vapor mixing coefficient $K$ as a function of height.

that the mixing length is proportional to the characteristic scale of the turbulent eddies, which, in turn, is nearly constant with the height above this surface layer. On the other end of the scale, mixing on the scale of surface roughness depends on the existence of a laminar sublayer. If

$$
u_{*} \cdot \frac{z_{0}}{\nu}>2.5
$$

then we can talk about the aerodynamically rough flow, where viscous stress is smaller than eddy pressure forces from flow over surface roughness (there eventually has to be some laminar flow just next to the surface but only microscopically thin). Based on values presented in Figure 11, we expect this to be the case for the Viking lander sites.

Values used for the calculation are anchored at the bottom by the lander meteorology measurement, at the top by the GCM results, and partially by the lander descent wind measurement. The synthetic atmospheric profile is summarized in Figure 11, zonal winds and water vapor mixing coefficient as a function of height.

\section{Quantitative Test of Model at VL 2 Site}

In this section, we compare the environmental observations with expectations based upon our model. First, we present arguments based on the changes in frost surface coverage and its timing of transition as compared with frost stability. Second, evidence from the water vapor column abundance and the vertical transport in the Martian atmosphere will be discussed.

\section{Frost Surface Coverage, Its Color and Timing of Transition}

Changes of frost surface coverage and color as a function of $L_{s}$ are plotted in Figure 12. Note the sharp transition from full coverage of the surface by frost to partial coverage (typically 15\%). There were parallel color changes of the frost layer (also Figure 12). The disappearing frost was getting redder. This can be attributed to breaking up the surface layer and seeing more of the underlying reddish surface. On the other hand, the frost which was "destined" to stay (that is is the frost in the locally favorable areas, behind rocks, in troughs) is getting whiter. This can be explained

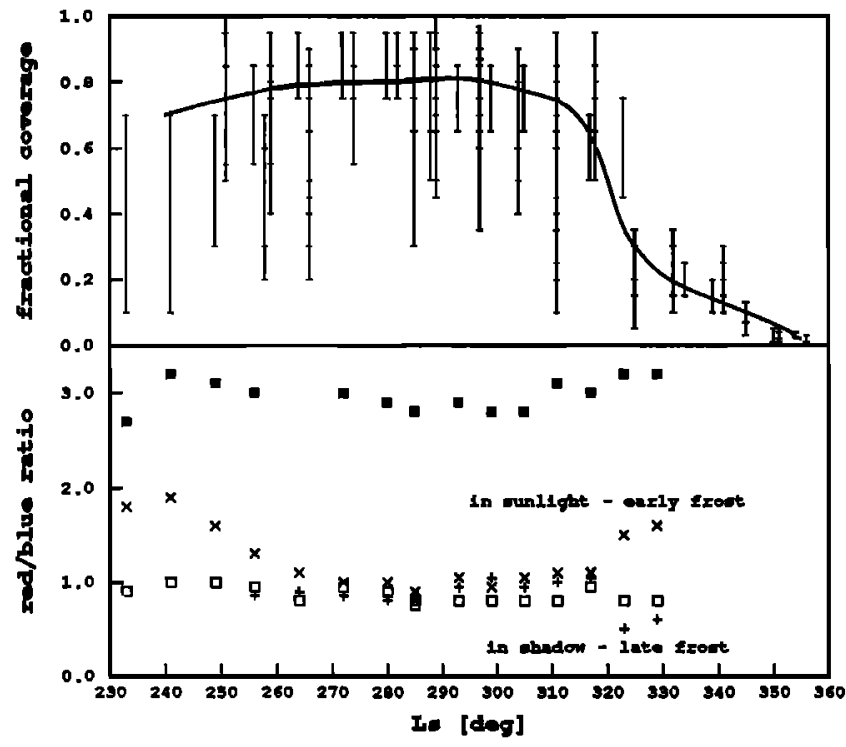

Fig. 12. Changes of frost surface coverage and color as a function of $L_{s}$. The solid squares are red/blue ratios from the red color on the VL 2 calibration target (typically, around 3.0). The empty squares are red/blue ratios from the white color on the VL 2 calibration target (typically around 1.0). The crosses represent the averaged color of the typical frost which disappeared quickly around $L_{s} \approx 325$. The pluses represent the color of the late frost which stayed longer and was getting "whiter" (less red) during the general disappearance of most of the frost.

either by a thicker layer of the water frost over red substrate or by a purer composition of recondensed frost (less dust/ice mixture).

It is interesting to compare the timing of the above mentioned transition from the full to partial surface coverage accompanied by color changes of frost. This transition occurred the first winter around $L_{s}=325^{\circ}$ and a few degrees earlier the second winter. Note that in Figure 10 it is approximately (within $5^{\circ}$ ) the time when the sublimation capability of sunlight reaches the thickness that could be expected of typical continuous coverage frost, $20-50 \mu \mathrm{m}$. Therefore we can conclude that the time of transition (as seen in imaging) coincides with expected transition derived from energy balance calculation.

Also note the steep slope of the solar heat input and its derived frost sublimation capability. It means that for a large portion of winter, insolation substantially lacks the energy necessary to sublime a significant amount of water frost. However, once it reaches this capability, any realistic frost layer will be sublimed very quickly (within a few days) and frost is stable only in sheltered areas, cold traps.

\section{Water Vapor in Atmosphere: Holding Capacity and Vertical Mixing}

Further tests of the model at VL 2 site can be based on the MAWD data on water vapor column abundance and its relation to the atmospheric transport of water vapor. Meridianal transport of water vapor has to be limited for sublimed water vapor to be redeposited in local cold traps. Otherwise, meridianal transport will advect water vapor equatorward where it does not have to be deposited as a surface frost because atmospheric holding capacity is large compared with amount of sublimed water vapor. Meridianal advection at 
the boundary layer itself is quite limited; water vapor has to get mixed in the atmosphere above this layer. This requires rather substantial vertical mixing of the water vapor toward altitudes above the boundary layer. In reality, the vertical mixing is limited at this latitude and season because of close to saturation of the atmosphere. For most of the winter, atmosphere at this latitude (VL 2 site) is saturated with water vapor during the night and above the thermal boundary during the day. This statement is based on the atmospheric temperature data and on the MAWD data (compare Figures 5 and 6). There were about 5-8 precipitable $\mu \mathrm{m}$ of water in the total atmospheric column (most of it within the first two scale heights). This is also supported by the evidence of morning fogs [Pollack et al., 1979; Jakosky, 1985; Jakosky et al., 1988] and temperature inflection at the lander sites [Ryan and Sharman, 1981].

Figure 13 shows the estimated effect of vertical mixing of water into the almost saturated atmosphere. The figure shows the diurnal cycle in the water vapor column abundance for a period of 10 sols. There is a rapid increase in the water vapor column abundance around noon because the atmospheric thermal boundary layer approaches its highest temperature then. Afterward, there is a slow decrease in the water vapor column abundance because the thermal boundary cools down and the water vapor is redeposited from the atmosphere back on the surface. There is always a slight secular increase in the water vapor column abundance due to an increased temperature of the whole atmosphere and also because of slow mixing (leaking) of water vapor from the boundary layer to the higher altitudes where water vapor is advected equatorward. This rate of increase in the water vapor column abundance is denoted by line $A$.

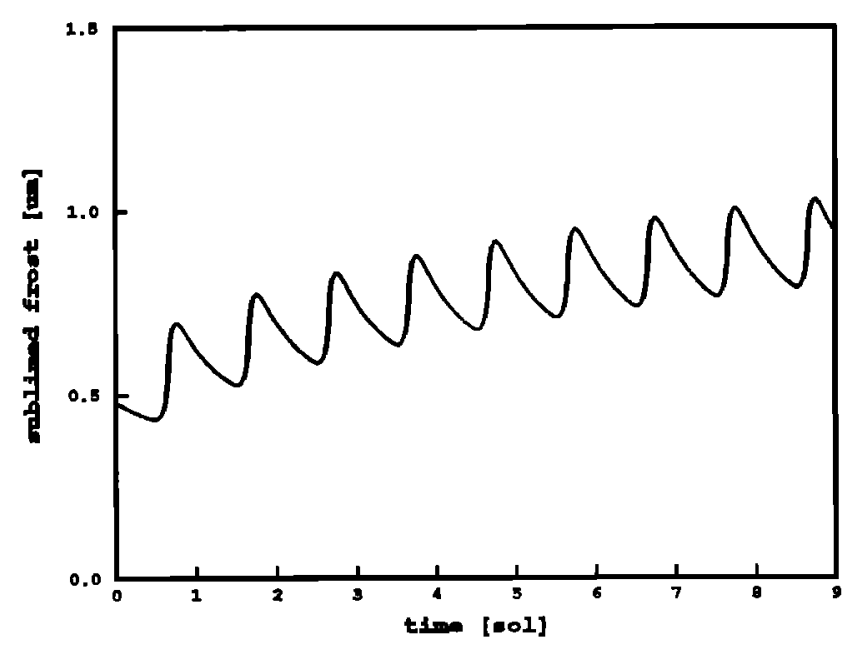

Fig. 13. Estimated vertical mixing in the boundary layer. The approximate calculation of the residual water vapor content in the atmospheric boundary layer on a diurnal cycle. It is important to note that the true sublimation of the frost from the surface by solar insolation is the secular trend of the curve averaged over several sols (line A). The immediate sublimation rate (around the noon on each day) is much higher (line B, compare with Figure 10), but most of water vapor condenses back on the surface (cold trapping). This calculation does not take into account the possibility of free convection during the warmest parts of a sol (very unstable atmosphere). The mixing in the boundary layer would be faster with the free convection but still does not reach the rates given by thermodynamical calculation.
The "leakage" from the boundary layer upward, that is, a loss from the diurnal cycle of cold trapping, can be estimated as follows: a $\theta$ probability that a water molecule will be redeposited in a cold trap within one day is approximately the product of (1) a $\sigma$ fraction of surface covered by cold traps, (2) a "sticking" coefficient for water molecule in a water frost (which we assume at these temperatures to be close to one, about 0.8 [Adamson, 1982]), and (3) the number of times a water molecule has a chance to hit surface. The last factor is just a ratio of the diurnal vertical distance traveled by random turbulence motion in the boundary layer over the eddy diffusion layer thickness. Therefore

$$
\theta \sim \sigma \cdot 0.8 \cdot \bar{w}^{\prime} \cdot \sqrt{\frac{t_{D}}{K}}
$$

where $w^{\prime}$ is the average deviation from the mean vertical velocity $(\approx 5 \mathrm{~m} / \mathrm{s}), t_{D}$ is the duration of the day, and $K$ is the eddy diffusion coefficient $\left(\approx 10^{2} \mathrm{~m}^{2} \mathrm{~s}^{-1}\right.$, Figure 11 and Jakosky [1985]). For $\sigma \approx 0.1$ (typical for the VL 2 site), we get $\theta$ close to one (within a factor of 2).

The numerical diffusion model (shown in Figure 13) with the parameters for mixing in the boundary layer as presented in the previous section gives a diurnal cold trapping efficiency equal to 0.9 and thus confirms the estimate above.

\section{Conclusions About Quantitative Tests}

There are three primary conclusions to be derived from the quantitative test of our hypothesis at the VL 2 site. First, there is a transition in frost surface coverage and color. The timing of the transition is consistent with the layer thickness derived from the amount of water vapor in the atmosphere before winter frost formation $(10-30 \mu \mathrm{m})$. The timing of disappearance of the frost in cold traps in consistent with the thickness of 100-200 $\mu \mathrm{m}$. The change in color (from slightly reddish tint to, probably, "bluish" tint) is consistent with the fresh frost redeposition into cold traps where it covers the mixture of thin frost and dust.

Second, there is no comparable increase in the atmospheric water vapor column during the transition, not until about $20^{\circ} L_{s}$ later. In the meantime, the water had to be stored somewhere because we see disappearance of the continuous frost coverage. This is consistent with the most of water stored in the cold traps as a frost.

Third, there is not much chance of water vapor being advected quickly (i.e., within a few sols) to the lower latitudes. The vertical mixing in the boundary layer of the almost saturated winter atmosphere is very limited, and therefore water vapor cannot get into higher altitude and thus being transported globally. It has to stay close to the ground where chances of hitting the surface at the cold traps is close to one on diurnal time scale.

From these three arguments, we can conclude that our hypothesis about cold trapping of water frost at the VL 2 site is consistent with the quantitative tests described in this section.

\section{Discussion AND CONCLUSIONS}

In this paper we have presented quantitative evidence for cold trapping at the VL 2 site. This evidence consists of the frost surface coverage and color transition, timing of this transition, and limited vertical mixing and horizontal water 
vapor transport. Moreover, we believe that cold trapping must be a general property of seasonal frost and therefore must be considered in order to understand the evolution of the VL 2 winter frost and the surface environment of Mars in general.

One consequence of the theory is an effective delay by about $20^{\circ}$ of $L_{s}$ in release of water which was condensed as a surface frost during the winter. Indeed, the possible difference between the latitude of the peak water vapor column abundance and the latitude of the edge of the retreating $\mathrm{CO}_{2}$ seasonal ice cap may require a mechanism for delayed release of water. Both the surface temperature and water vapor column abundance as a function of $L_{s}$ are presented in Figure 14 for the northern seasonal cap during the spring. The surface temperature (upper curve) is measured by the $20-\mu \mathrm{m}$ band of the IRTM instrument. The drop to $150 \mathrm{~K}$ surface temperature occurs at the latitude of the edge of the seasonal $\mathrm{CO}_{2}$ frost. The boundary is not sharp because the data were binned in $2^{\circ}$ bins in latitude and averaged around Mars in longitude. The water vapor column abundance data (lower curve) were measured by the MAWD instrument and again averaged in $2^{\circ}$ steps in latitude and around Mars in longitude. The data in Figure 14 are an average for the period of $L_{s}=50^{\circ}-60^{\circ}$.

If we assume that the $\mathrm{CO}_{2}$ seasonal frost acts as a sink for water vapor seen in the atmosphere during the summer and early fall, then we should expect the edge of the retreating seasonal cap to behave as a source for atmospheric water vapor. There could be, of course, no release of water vapor before the $\mathrm{CO}_{2}$ frost retreats. However, once the $\mathrm{CO}_{2}$ sublimes, the water vapor should appear in the atmosphere rather quickly and then be transported equatorward. Therefore the peak of water vapor column abundance should occur just above the edge of the retreating seasonal cap which is not the case in Figure 14. However, the peak of water vapor is southward from the edge of the retreating seasonal cap by about $10^{\circ}$ in latitude, which corresponds to the delay of about $20^{\circ} L_{s}$, or 35 sols.

This is a global phenomenon and could arise from (1) seasonal water vapor release from the regolith, not from the

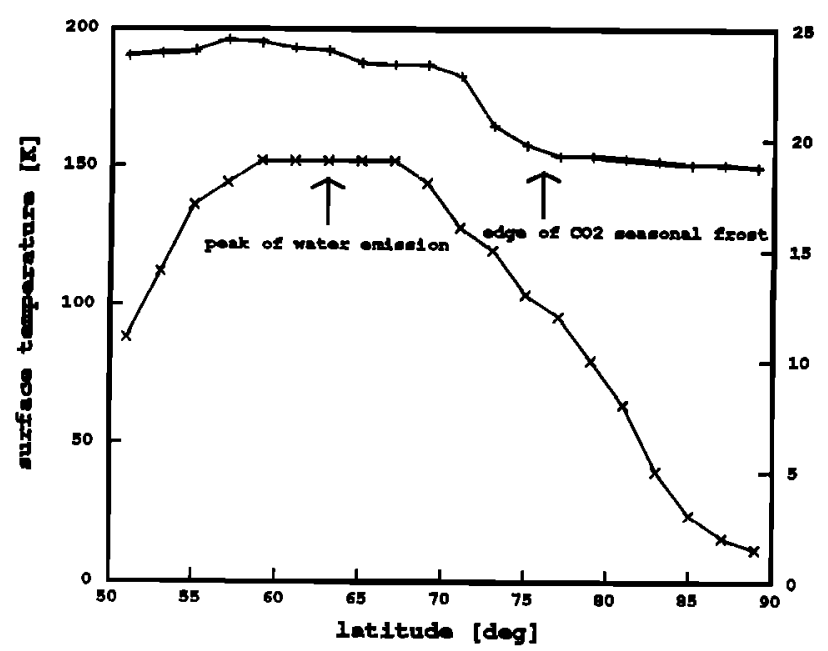

Fig. 14. Difference between the latitude of the peak water vapor column abundance (as seen in the MAWD instrument on Viking orbiter) and the latitude of the edge of the retreating $\mathrm{CO}_{2}$ seasonal ice cap (a sharp drop of IRTM surface temperature toward $150 \mathrm{~K})$.
$\mathrm{CO}_{2}$ frost, (2) residual water frost substrate below the seasonal $\mathrm{CO}_{2}$ frost being released gradually as the surface slowly heats up, (3) observational effect of clouds, (4) temporary water storage in clouds, or (5) water frost temporarily locked in local cold traps created by small-scale surface roughness as we have interpreted happened locally at the VL 2 site.

The first possibility (seasonal water vapor release from the regolith) requires either unrealistic high regolith permeability to repeatedly release several tens of precipitable micrometers of water during the spring for many years or continuous replenishment from the atmosphere during other seasons. The continuous replenishment mechanism is based on a rigorous model [Jakosky, 1983]. However, we have doubts about the initial assumption of this model: the equal value of a diffusion constant for diffusion in and out of regolith. Some models of microphysics of diffusion of vapor through regolith could yield higher values for a diffusion constant of water vapor from the regolith as compared with the diffusion back into the regolith from the atmosphere. Therefore we believe that further work may still be needed to decide about this possible directional asymmetry in the diffusion constant.

The second possibility (residual water frost substrate gradually released) falls far short of providing the observed delay of water release. One sol is quite sufficient to raise the temperature of a sunlit fraction of the surface from $150^{\circ} \mathrm{K}$ to $190^{\circ} \mathrm{K}$ (equilibrium temperature for the latitude of $65^{\circ}$ in Figure 14). Therefore it would be quite difficult to use this explanation as basis for the $\mathbf{3 5}$ sol delay. Also, there is no evidence in Viking orbiter imaging to support the existence of this water ice substrate below $\mathrm{CO}_{2}$ seasonal frost.

The third possibility (observational effect of water vapor clouds) suffers from the fact that the polar hazes extend at most only a few degrees south of the polar cap edge [Christensen and Zurek, 1984]. The difference in latitudes in Figure 14 is larger than that (about $10^{\circ}$ ).

The fourth possibility (water storage in clouds) does not provide a reservoir which would be large enough. The optical depth of hazes is about unity which corresponds to only 1-2 precipitable micrometers of water ice [Christensen and Zurek, 1984].

Finally, the fifth possibility (the cold-trapping model proposed in this paper) seems to be consistent with all the observations. We, obviously, do not have a direct evidence, only a set of circumstantial observations and physical arguments as described in the previous section. And, of course, we cannot exclude that a combination of effects mentioned above, possible with others which we did not put forth, will provide the consistent explanation. Still, the cold trapping of water due to small-scale roughness could be the relevant model for the global behavior of water on Mars.

This assertion is based on the following model: once the water vapor sublimation becomes possible (i.e., after disappearance of the seasonal $\mathrm{CO}_{2}$ frost), in a very short time $(\approx 1 \mathrm{sol}) 20$ precipitable $\mu \mathrm{m}$ of water vapor can be released into the atmosphere. However, the long-range transport is limited, due to still relatively cold atmosphere and slow mixing through the boundary layer. Therefore water vapor can be transported only over relatively short distances (at most few tens of kilometers). But the water vapor gets into contact with surface during the transport through boundary layer, and it is redeposited back on the surface, preferen- 
tially at the colder areas created by the small-scale roughness (i.e., in cold traps). Eventually (in $20^{\circ} L_{s}$ ), continuous transport through the atmospheric boundary layer coupled with the increased atmospheric temperature will allow all water frost to sublime away, even at the cold traps.

In order to verify if this proposed mechanism plays a general on Mars, we need better data than those provided by the Viking mission. Mars Observer is expected to provide at least two potential measurements which could verify this theory: First, there should be a small but consistent discontinuous albedo change of the water frost at the time when the surface energy balance will allow water to sublime. This may be interpreted in terms of water frost recondensation. Such data could be provided by the Mars Observer Camera (albedo) and Thermal Emission Spectrometer (surface temperature). It is not clear whether the postulated color change could be measured with the Mars observer instrumentation without the Visual Imaging Mapping Spectrometer which unfortunately has been dropped from the payload. Second, the phase lag in water release to the atmosphere from the seasonal $\mathrm{CO}_{2}$ frost could be observed by Pressure Modulated Infrared Radiometer (water vapor content in the atmosphere) and again Thermal Emission Spectrometer (presence of $\mathrm{CO}_{2}$ or water frost on the surface). However, there are still some Viking orbiter measurements (improved correlation of unbinned IRTM and MAWD data) which could be used to gather more support for this model and recalibrated Viking and Mariner 9 images could reveal evidence for this effect as well. The potential of surface measurements of water vapor (from rovers, balloons, etc.) should also be explored in order to measure the seasonal and diurnal behavior of water on the surface of Mars.

Acknowledgments: We wish to express our sincere thanks for the helpful discussion and suggestions to Andrew Ingersoll, David Stevenson, David Crisp, Bruce Jakosky, Richard Zurek, David Paige, James Tilman, and Henry Moore. The Viking IRTM, MAWD, and lander meteorology data were accessed through the PDS Prototype Node: Planetary Atmospheres located at Laboratory for Atmospheric and Space Physics, University of Colorado, Boulder. We thank Steve Lee and others at LASP for their dedicated work on this system which greatly facilitates the access to the planetary spacecraft data. This work was partially supported by NASA grant NAGW-1373. Contribution 4698 of the Division of Geological and Planetary Sciences, California Institute of Technology, Pasadena, California.

\section{REFERENCES}

Adamson, A. W., Physical Chemistry of Surfaces, John Wiley, New York, 1982.

Arvidson, R. E., E. A. Guinness, H. J. Moore, J. Tillman, and S. D. Wall, Three Mars years: Viking lander 1 imaging observations, Science, 222, 463-465, 1983.

Brutsaert, W., Evaporation Into the Atmosphere, D. Reidel, Hingham, Mass., 1982.

Carr, M. H., Mars: A water-rich planet?, Icarus, 68, 187-216, 1986.

Christensen, P. R., and R. W. Zurek, Martian north polar hazes and surface ice: Results from the Viking survey/completion mission, J. Geophys. Res., 89, 4587-4596, 1984.

Clark, R. N., The surface condensates on Mars observed by Viking: Frost layers several tenths of a millimeter thick, $\mathbf{L u}$ nar Planet. Inst., 160-161, 1980.

Clifford, S. M., and D. Hillel, Knudsen diffusion: The effect of small pore size and low gas pressure on gaseous transport in soil, Sol Sci., 141, 289-297, 1986.

Davies, D. W., C. B. Farmer, and D. D. LaPorte, Behavior of volatiles in Mars' polar areas: A model incorporating new experimental data, J. Geophys. Res., 82, 3815-3822, 1977.
Davies, D. W., The vertical distribution of Mars water vapor, $J$. Geophys. Res., 84, 2875-2879, 1979a.

Davies, D. W., The relative humidity of Mars' atmosphere, $J$. Geophys. Res., 84, 8335-8340, 1979b.

Dorsey, N. E., Properties of Ordinary Water-Substance, Reinhold, New York, 1940.

Flasar, F. M., and R. M. Goody, Diurnal behavior of water on Mars, Planet Space Scr. Rev., 34, 161-181, 1975.

Guinness, E. A., R. E. Arvidson, D. C. Gehert, and L. K. Bolef, Color changes at the Viking landing sites over the course of a Mars year, J. Geophys. Res., 84, 8355-8364, 1979.

Guinness, E. A., C. E. Leff, and R. E. Arvidson, Two Mars years of surface changes seen at the Viking Landing sites, J. Geophys. Res., 87, 10,051-10,058, 1982.

Hart, H. M., and B. M. Jakosky, Composition and stability of the condensate observed at the Viking lander 2 site on Mars, Icarus, 66, 134-142, 1986.

Hess, S. L., R. M. Henry, C. B. Leovy, J. A. Ryan, and J. E. Tillman, Meteorological results from the surface of Mars: Viking 1 and 2, $J$. Geophys. Res., 82, 4559-4574, 1977.

Holton, J. R., An Introductron to Dymamic Meteorology, Academic, San Diego, Calif., 1979.

Ingersoll, A. P., Mars: Occurrence of liquid water, Science, 168, 972-973, 1970.

Ingersoll, A. P., Mars: The case against permanent $\mathrm{CO}_{2}$ frost caps, J. Geophys. Res., 79, 3403-3410, 1974.

Jakosky, B. M., The effects of nonideal surfaces on the derived thermal properties of Mars, J. Geophys. Res., 84, 8252-8262, 1979.

Jakosky, B. M., The role of seasonal reservoirs in the Mars water cycle, I, Seasonal exchange of water with the regolith, Icarus, $55,1-18,1983$.

Jakosky, B. M., The seasonal cycle of water on Mars, Space Sci. Rev., 41, 131-200, 1985.

Jakosky, B. M., On the thermal properties of Martian fines, Icarus, $66,117-124,1986$.

Jakosky, B. M., R. W. Zurek, and M. R. La Pointe, The observed day-to-day variability of Mars atmospheric water vapor, Icarus, $73,80-90,1988$.

Jones, K. L., R. E. Arvidson, E. A. Guinness, S. L. Bragg, S. D. Wall, C. E. Carlston, and D. G. Pidek, One Mars year: Viking Lander imaging observations of sediment transport and $\mathrm{H}_{2} \mathrm{O}$-condensates, Science, 204, 799-806, 1979.

Kieffer, H. H., T. Z. Martin, A. R. Peterfreund, B. M. Jakovsky, E. D. Miner, and F. D. Palluconi, Thermal and albedo mapping of Mars during the Viking primary mission, J. Geophys. Res., $82,4249-4291,1977$.

Leighton, R. B., and B. C. Murray, Behavior of carbon dioxide and other volatiles on Mars, Science, 159, 136-144, 1966.

Lindal, G. F., H. B. Hotz, D. N. Sweetnam, Z. Shippony, J. P. Brenkle, G. V. Hartsell, R. T. Spear, and W. H. Michael, Jr., Viking Radio occultation measurements of the atmosphere and topography of Mars: Data acquired during 1 Martian year of tracking, J. Geophys. Res., 84, 8443-8456, 1979.

Moore H., R. E. Hutton, G. D. Clow, and C. R. Spitzer, Physical properties at the Viking lander sites, U.S. Geol. Surv. Prof. Pap., $1989,1987$.

Pollack, J. B., Properties and effects of dust particles suspended in the Martian atmosphere, J. Geophys. Res., 84, 2929-2945, 1979.

Pollack, J. B., C. B. Leovy, P. W. Greiman, and Y. Mintz, A Martian general circulation experiment with large topography, JAS, 38, 3-29, 1981.

Plate, E. J., Aerodynamic Characterzatics of Atmospheric Boundary Layers, AEC Crit. Rev. Ser., AEC, Oakridge, Tennessee, 1971.

Priestley, C. H. B., Turbulent Transfer in the Lower Atmosphere, University of Chicago Press, Chicago, Ill., 1959.

Ryan, J. A., and R. D. Sharman, Water frost point detection on Mars?, J. Geophys. Res., 86, 503-511, 1981.

Seiff, A., and D. B. Kirk, Structure of the atmosphere of Mars in summer at mid-latitudes, J. Geophys. Res., 82, 4364-4378, 1977.

Sharp, R. P. and M. Malin, Surface geology from Viking Landers on Mars: Second look, Geol. Soc. Am. Bull., 95, 1398-1412, 1984.

Smith, A. M., K. E. Tempelmeyer, P. R. Müller, and B. E. Wood, Angular distribution of visible and near IR radiation reflected from $\mathrm{CO}_{2}$ cryodeposits, AIAA J., 7, 2274-2280, 1969. 
Snyder, C. W., The planet Mars as seen at the end of Viking mission, J. Geophys. Res., 84, 8487-8519, 1979.

Sutton, J. J., C. B. Leovy, and J. E. Tillman, Diurnal variations of the Martian surface layer meteorological parameters during the first 45 sols at the Viking lander sites, JAS, 35, 2346-2355, 1979.

Sutton, O. G., Micrometeorology, McGraw-Hill, New York, 1953.

Toon, O. B., J. B. Pollack, W. Ward, J. A. Burns, and K. Bilski, The astronomical theory of climate change on Mars, Icarus, 44, 552-607, 1980.

Wall, S. D., Analysis of condensates formed at the Viking 2 Lander site-The first winter, Icarus, 47, 173-183, 1981.

Warren, S. G., Optical properties of snow, Rev. Geophys., 20, 67$89,1982$.
Zent, A. P., F. P. Fanale, J. R. Salvail, and S. E. Postawko, Distribution and state of water in the high-latitude shallow subsurface of Mars, Icarus, 67, 19-36, 1986.

Zurek, R. W., Martian great dust storms: An update, Icarus, 50, 288-310, 1982.

B. Murray and T. Svitek, Division of Geological and Planetary Sciences, California Institute of Technology, Pasadena, CA 91125.

(Received September 13, 1988; revised May 4, 1989; accepted May 16, 1989.) 